\title{
Investigating slow-moving landslides in the Zhouqu region of China using InSAR time-series
}

\author{
Zhang, $\mathrm{Yi}^{\mathrm{a}, \mathrm{b}}$, Meng, Xingmin a,b,* ${ }^{\mathrm{a}}$, Jordan, Colm c ${ }^{\mathrm{c}}$, Novellino, Alessandro ${ }^{\mathrm{c}}$, Dijkstra, Tom ${ }^{\mathrm{c}, \mathrm{d}}$, Chen Guan ${ }^{\mathrm{a}, \mathrm{b}}$ \\ ${ }^{a}$ MOE Key Laboratory of Western China's Environmental Systems, College of Earth and Environmental Sciences, Lanzhou \\ University, Lanzhou, 730000, P. R. China \\ ${ }^{b}$ Gansu Environmental Geology and Geohazards Engineering Research Centre, College of Earth and Environmental \\ Sciences, Lanzhou University, Lanzhou, 730000, P. R. China \\ ${ }^{c}$ British Geological Survey, Nottingham NG12 5GG, UK \\ ${ }^{d}$ School of Architecture, Building and Civil Engineering, Loughborough University, Loughborough, LE11 3TU, UK \\ * Corresponding author (E-mail: xmmeng@lzu.edu.cn)
}

\begin{abstract}
In the Zhouqu region (Gansu, China), landslide distribution and activity exploits geological weaknesses in the faultcontrolled belt of low-grade metamorphic rocks of the Bailong valley and severely impacts lives and livelihoods in this region. Landslides reactivated by the Wenchuan 2008 earthquake and debris flows triggered by rainfall, such as the 2010 Zhouqu debris flow, have caused more than 1700 casualties and estimated economic losses of some US\$0.4 billion. Earthflows presently cover some $79 \%$ of the total landslide area and have exerted a strong influence on landscape dynamics and evolution in this region. In this study, we use multi-temporal Advanced Land Observing Satellite and Phased Array type L-band Synthetic Aperture Radar (ALOS PALSAR) data and time series interferometric synthetic aperture radar to investigate slow-moving landslides in a mountainous region with steep topography for the period December 2007-August 2010 using the Small Baseline Subsets (SBAS) technique. This enabled the identification of 11 active earthflows, 19 active landslides with deformation rates exceeding $100 \mathrm{~mm} /$ year and 20 new instabilities added into the pre-existing landslide inventory map. The activity of these earthflows and landslides exhibits seasonal variations and accelerated deformation following the Wenchuan earthquake. Time series analysis of the Suoertou earthflow reveals that seasonal velocity changes are characterized by comparatively rapid acceleration and gradual deceleration with distinct kinematic zones with different mean velocities, although velocity changes appear to occur synchronously along the landslide body over seasonal timescales. The observations suggest that the post-seismic effects (acceleration period) on landslide deformation last some 6-7 months.
\end{abstract}

Keywords Zhouqu • Landslide $\cdot$ Earthflow $\cdot$ InSAR Deformation · Seismic effects

\section{Introduction}

Landslides play a prominent role shaping landscapes through the episodic redistribution of materials under lithological, climatic, and tectonic control (Burbank and Anderson 1985; Korup et al. 2010; Crosta et al. 2013). Consequently, landslides can cause significant structural, social, and economic impacts, particularly in areas under pressure from ongoing urbanization and infrastructure development (Schuster and Highland 2007; Del Soldato et al. 2017). An improved understanding of displacement characteristics of landslides combined with an analysis of their geomorphological setting can assist the reconstruction of the long-term evolution of landscapes 
(Agliardi et al. 2013). In addition, investigation of landslides and ground deformation patterns results in an enhanced capacity to design, construct, and manage appropriate landslide risk reduction infrastructure and strategies.

The Zhouqu region, located in the middle reaches of the Bailong River Corridor, is characterized by high mountains and deeply incised valleys providing limited suitable space for regional development and construction. Large landslides and debris flows form a frequently occurring geohazard posing significant risk to lives and livelihoods. This is illustrated by the re-activation of large landslides by the Wenchuan earthquake (May 12, 2008) (Yin et al. 2009) and the disastrous, rainfall-triggered debris flow that occurred on October 8, 2010, resulting in more than 1700 fatalities and a gross-estimated economic loss exceeding US\$0.4 billion (Tang et al. 2011; Bai et al. 2012; Dijkstra et al. 2012; Cui et al. 2013). Slow-moving, deep-seated earthflows (Varnes 1978; Hungr et al. 2014) form a dominant landslide category in the Zhouqu study region; a detailed analysis of surface displacements can help understand their potential to cause significant harm to lives and livelihoods (Hungr et al. 2014; Teshebaeva et al. 2015; Calvello et al. 2017). The displacement rates of earthflows range from a few millimeters per year to more than $1 \mathrm{~m} /$ year and are often characterized by long periods of relatively slow movements (with deformation most likely concentrated along the main shear surface) interspersed by surges in movement (when multiple shear surfaces can become active, distributing internal strains and resulting in a flowlike morphology; Hungr et al. 2014). These surges in movement are often triggered by external disturbances such as prolonged or excessive rainfall and/or seismic shocks that can lead to a cascade of elevated pore pressures and loss of shearing resistance (Mansour et al. 2011; Travelletti et al. 2014; Schlögel et al. 2016). In some cases, the mobility of earthflows is a response to the rise and fall in groundwater levels or soil moisture changes due to thawing soils, rainfall, or snowmelt (Malet et al. 2005; van Asch et al. 2007). Field monitoring and geomorphological observations play an important role in deriving an appropriate suite of assumptions that feed into numerical simulations (Malet et al. 2005).

Compared to traditional methods such as Global Navigation Satellite System (GNSS), optical remote sensing, and geophysical surveys on regional or basin scales, the interferometric synthetic aperture radar (InSAR) technique is one of the most efficient methods for slow-moving landslide observation, monitoring, interpretation, and assessment, due to its high accuracy, large coverage, and long-term acquisition under all weather conditions (Bürgmann et al. 2000; Hanssen 2001; Cigna et al. 2013; Wasowski and Bovenga 2014; Zhang et al. 2016; Calvello et al. 2017). A wide range of algorithms have been developed to produce InSAR time series of ground deformation and minimize errors associated with temporal decorrelation and topography (Osmanoğlu et al. 2016). The time series InSAR method has been applied successfully in a range of landslide studies, not only to locate landslides, but also to identify spatial-temporal patterns of movement (Necsoiu et al. 2014; Wasowski and Bovenga 2014; Zhang et al. 2016; Tomás et al. 2016; Bouali et al. 2017). Moreover, analysis of InSAR-generated displacement time series has the potential to identify periods of accelerated landslide deformation and to evaluate correlations with different triggers (rainfall, earthquakes).

We recognize that forecasting the movement of earthflows requires detailed observations of the geometry and, in particular, the observation of surface deformation in zones of compression and extension, coupled with careful reconstruction of basal slip surfaces. This study reports on the characterization of landslide dynamics in the Zhouqu region of China — a unique natural laboratory for studying large-scale landslides and their interactions with tectonic and meteorological processes shaping a regional landscape. In this region, PSInSAR (permanent scatterer InSAR) and SBAS (small baseline subset) techniques have been applied previously to detect ground deformation. 
Wasowski et al. (2014) detected ground deformation over $100 \mathrm{~mm} /$ year by processing X-band (COSMO-SkyMed) data acquired from 2010 to 2012 using PS. Sun et al. (2015) and Zhang et al. (2016) identified ground deformation $\geq 50$ mm/year from 2007 to 2010 using L-band (Advanced Land Observing Satellite and Phased Array type L-band Synthetic Aperture Radar (ALOS PALSAR)) and C-band (ENVISAT ASAR) data processed using the SBAS technique.

This study builds on this previous work and demonstrates the advantages and limitations of InSAR-derived ground deformation time series by combining the interpretations of these time series with field monitoring and geomorphological mapping/characterization of landslides at regional and slope scales. This multi-faceted approach enables careful evaluation of the geomorphological and geological controls on earthflows and their impacts on local topography. The Suoertou earthflow is used as an example to assess the possible controls (hydro-geological, geomorphological, anthropogenic) that affect movements of earthflows in this region.

\section{Study area}

The Zhouqu area sits in the upper-middle reaches of the Bailong River basin, just west of the confluence with the Min River in southern Gansu Province (Fig. 1). The study area forms part of the eastern margins of the Qinghai-Tibetan Plateau and lies to the south of the Chinese Loess Plateau and north of the Sichuan Basin in a region that has been identified as one of highest landslide susceptibility areas of China (Scheidegger and Ai 1987; Meng et al. 2013). This region has been significantly affected by the Indosinian (Triassic), Yanshan (JurassicCretaceous), and Himalayan (Miocene-present) orogenic deformations with several NWW-SEE trending and NEE-SWW trending active faults representing a complex tectonic system (Dewey and Burke 1973; Molnar and Stock 2009; Bai et al. 2012; Zheng et al. 2016).

The topography is characterized by rugged mountains and deeply incised valleys with elevations ranging from $1200 \mathrm{~m}$ to more than $4000 \mathrm{~m}$ a.s.l. which has a strong influence on local climate: high relative relief causes rainfall to concentrate in the high-altitude areas, with much less precipitation in the valleys, resulting in the so-called dry and hot valleys system in this region as defined in Yu et al. (2015).

The drainage consists of numerous deeply incised valleys and gullies that eventually feed into the Bailong River. The region is dissected by Guanggaishan-Dieshan (GD) thrust which is composed of three subparallel active faults: the North GD fault, the Pingding- Huama ( $\mathrm{PH}$ ) fault, and the Zhouqu fault (Fig. 1). As an indication of neotectonic activity in the region, Yu et al. (2012) reports a vertical slip rate of the PH fault strikes of $0.49 \pm 0.08$ to $1.15 \pm 0.28 \mathrm{~mm} /$ year.

Persistent stress accumulation on fault surfaces is also manifested in the form of numerous earthquakes. A most severe recent earthquake (the Ms. 7.9 Wenchuan earthquake of May 2008), with the epicenter approximately $320 \mathrm{~km}$ from our study area, induced 102 new landslides, re-activated many more landslides, and impacted the local economy by more than US\$0.4 billion in Zhouqu (Huang and Li 2009; Bai et al. 2012, 2013; Chen et al. 2014). The earthquake resulted in extensive crack systems in valley-based deposits, and this likely contributed to the initiation of a devastating debris flow on August 8, 2010. The debris flow event transported more than $1.4 \times 106 \mathrm{~m} 3$ of sediment, destroyed many buildings, and killed more than 1700 people in Zhouqu (Cui et al. 2013; Dijkstra et al. 2012; Xiong et al. 


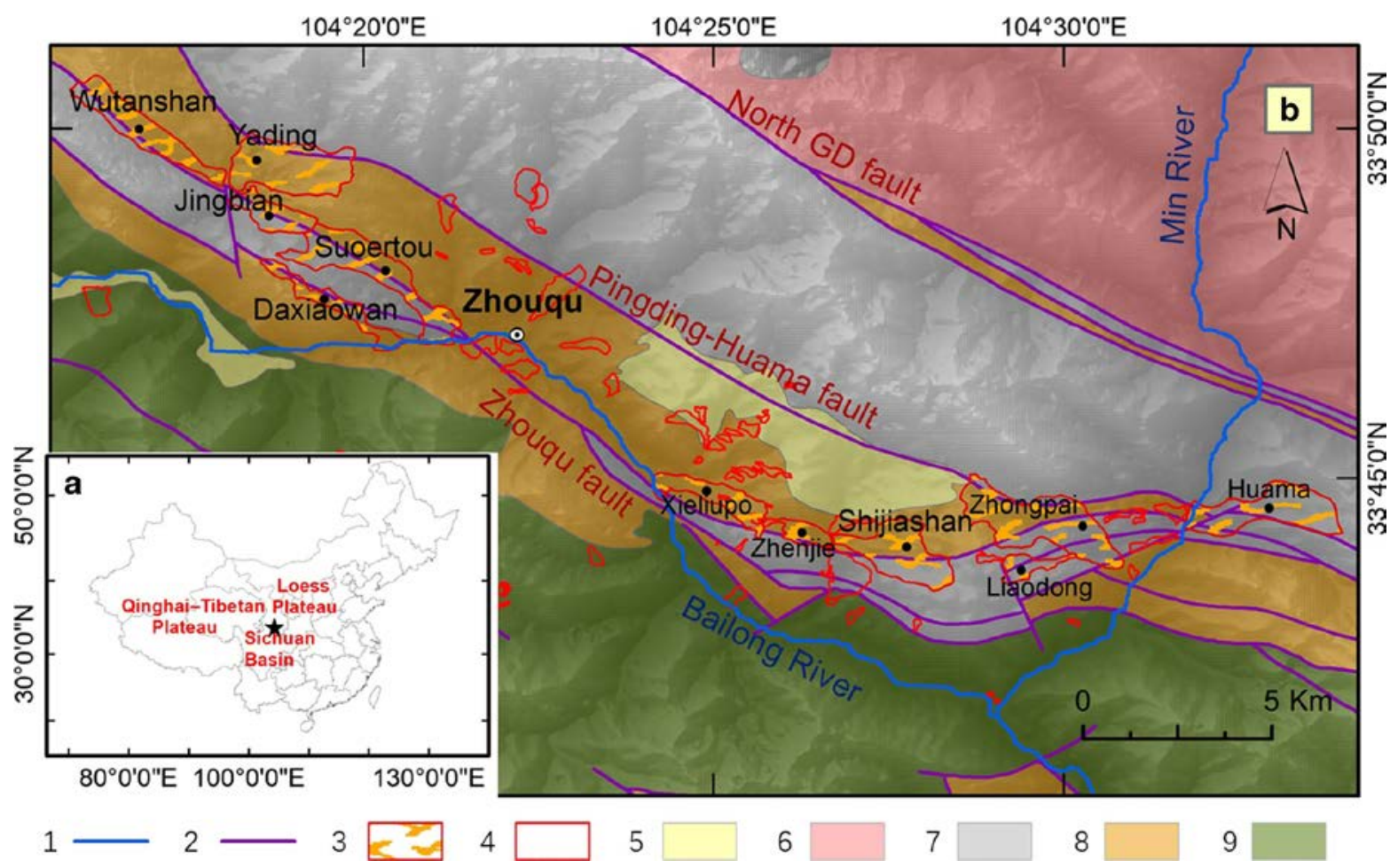

Fig. 1 Geological overview map of the Zhouqu region. (1) River; (2) faults; (3) earthflows; (4) other landslides; (5) Quaternary deposits (gravels and sands in the river valleys, silts and clays mainly on valley shoulders); (6) Triassic and Jurassic conglomerates, mudstones, siltstones, and shales; (7) Carboniferous and Permian limestones, dolomites, intercalated phyllites, slates, and shale; (8) Devonian slates and phyllites; (9) Silurian phyllites, sandy slates, sandstones, and intercalated limestones. Contains geological data from the Geological Environment Monitoring Institute of Gansu Province, China

\section{Datasets and methodology}

\subsection{Landslide inventory}

The pre-existing landslide inventory consisted of point locations generated from previous research (Bai et al. 2013; Chen et al. 2014; Yu et al. 2015). Enhancing this initial landslide distribution involved careful mapping of the landslides updating the points into polygons with additional attributes including movement direction, landslide type (according to Hungr et al. 2014), length, and area. We prepared the inventory using satellite imagery acquired by the ZY-3 satellite (sjfw.sasmac.cn/en/ZY-3.html), GoogleEarth ${ }^{\mathrm{TM}}$, Digital Terrain Model (DTM, $5 \mathrm{~m}$ spatial resolution), derived products (slope, hillshade), and 1:100,000 geology map (provided by the Geological Environment Monitoring Institute of Gansu Province, China) and validated it with literature review and field data. The initial landslide map was produced using remote sensing interpretation in ArcGIS and was modified through field surveys. The main objectives of the field surveys were to validate the remotely sensed mapped features and to better understand the characteristics of the landslides. The final map and landslide inventory includes 80 landslides, covering $28.8 \mathrm{~km}^{2}$ over a mapped area of approximately $400 \mathrm{~km}^{2}$. The main type of landslide comprises slow-moving earthflows (Fig.1). The 11 largest earthflows cover an area over $22 \mathrm{~km}^{2}$, representing more than $79 \%$ of the total area affected by landslides. The largest earthflow is $4500 \mathrm{~m}$ long and covers an area of $3.9 \mathrm{~km}^{2}$. Earthflows develop along or are in close proximity to the active faults while slip 
surfaces are often positioned along stratigraphical boundaries between Permian limestones, and Devonian limestones and slates. Some of them have been demonstrated to be active for a few decades, destroying roads and damming the Bailong River on several occasions (Yang et al. 2013; Jiang et al. 2016). Even though at present it does not appear likely that these earthflows will dramatically accelerate, their ongoing deformation coupled with the large volumes involved poses significant hazards to the development of this region.

\subsection{Topographic visibility}

Topographic settings play an important role in controlling the quality and quantity of ground motion information from InSAR data (Cigna et al. 2014; Notti et al. 2014). The SAR visibility of any area depends on the local terrain characteristics (slope and aspect) and satellite acquisition geometry (incident angle and heading angle), and it is represented by the R-Index (Notti et al. 2010; Cigna et al. 2014; Novellino et al. 2017). The latter is an indication of the ratio between the pixel size in slant and ground range geometry. To identify the geometrical distortions of SAR data, the R-Index and visibility were calculated using the formulas and criteria in Cigna et al. (2014) and Notti et al. (2014).

The topography of the Zhouqu region represents a major constraint on the efficacy of ALOS PALSAR data (Fig. 2), with shadow, layover and foreshortening affecting 2.6, 11.8, and 38.8\% of the landscape (corresponding to 15, 68.7, and $226 \mathrm{~km}^{2}$ over a total mapped area of $582 \mathrm{~km}^{2}$ ). The results of the geometric distortion show that shadow effects identified for ALOS PALSAR data are characterized by deeply incised valleys with slopes steeper than $52.3^{\circ}$. Areas resulting in layover are characterized by slopes facing West, with an R-index between -1 and 0 . The total area of all type of distortions is $83.7 \mathrm{~km}^{2}(\sim 14.4 \%)$, while the area of good visibility covers $272.6 \mathrm{~km}^{2}(\sim 46.8 \%)$. Fortunately, most of the mapped landslide polygons are located in areas with higher R-index values, providing a good opportunity to monitor displacements.

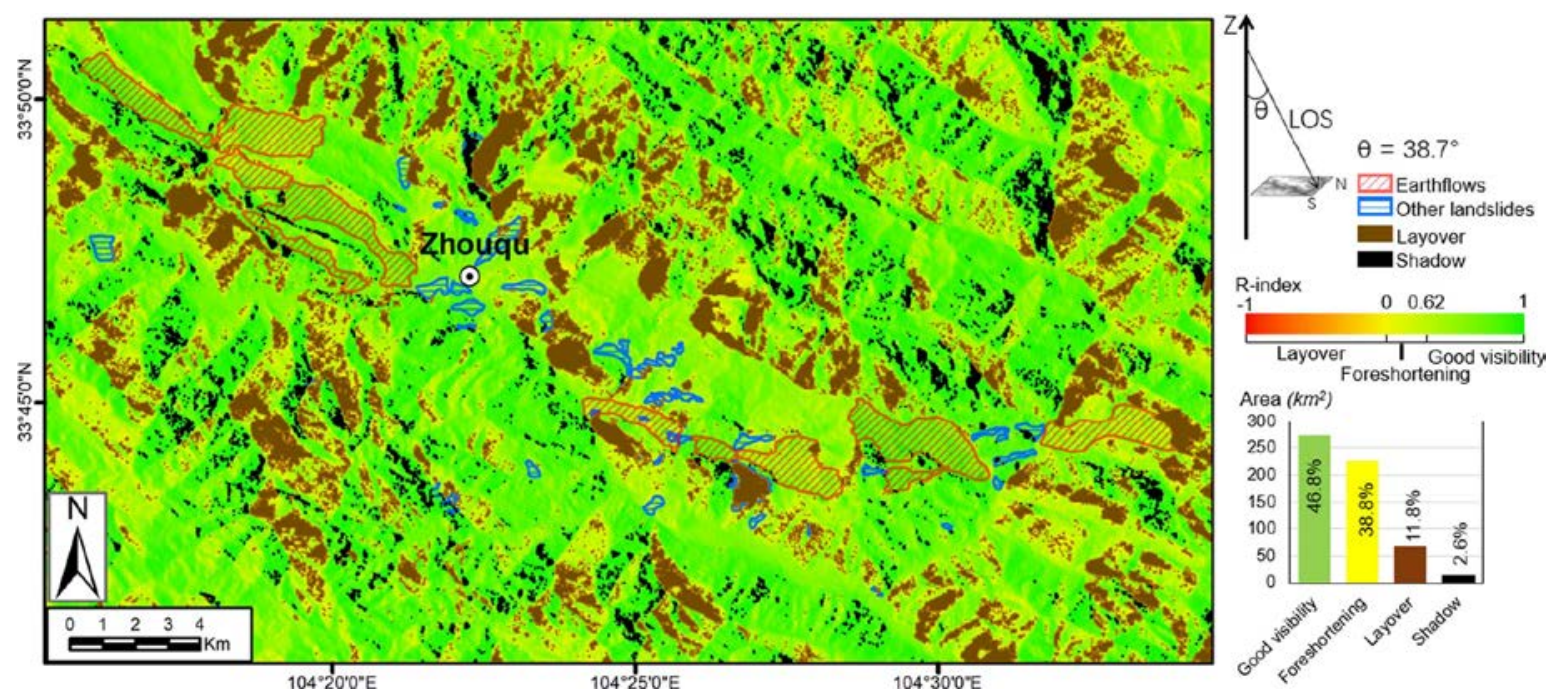

Fig. 2 Topographic distortions and terrain visibility to the ALOS PALSAR LOS geometry in ascending mode over Zhouqu region. The histogram shows total area statistics which are based on the $30 \mathrm{~m}$ SRTM

\subsection{InSAR}

In this paper, the SBAS technique is combined with geomorphological investigations to obtain a detailed distribution of 
active landslides and assess, from their temporal displacement patterns, the possible influence of the 2008 Wenchuan earthquake. To enable this, 16 ascending ALOS PALSAR images acquired from December 2007 to August 2010, with the central incident angle of $37.7^{\circ}$, were processed using the better ability of L-band SAR data to detect large and faster landslide deformation (Chen et al. 2013; Schlögel et al. 2015; Zhao et al. 2016). The ALOS PALSAR data were provided by the Japan Aerospace Exploration Agency (JAXA) with a HH polarization including eight scenes of fine beam single polarization and eight scenes of fine beam dual polarization. To reduce the decorrelation over a large area, a small subset of images was selected, covering a $436 \mathrm{~km}^{2}$ study area. The 1-arcsecond ( $\left.30 \mathrm{~m}\right)$ Shuttle Radar Topography Mission (SRTM) DEM data from the United StatesGeological Survey(USGS) wasused(1)toremovethetopographic phase and (2) for geocoding the InSAR products.

All SBAS steps (Berardino et al. 2002) were processed using SARscape software (Sarmap 2005). For a small number $(<20)$ of images, the SBAS technique was selected to obtain deformation results.

2016).

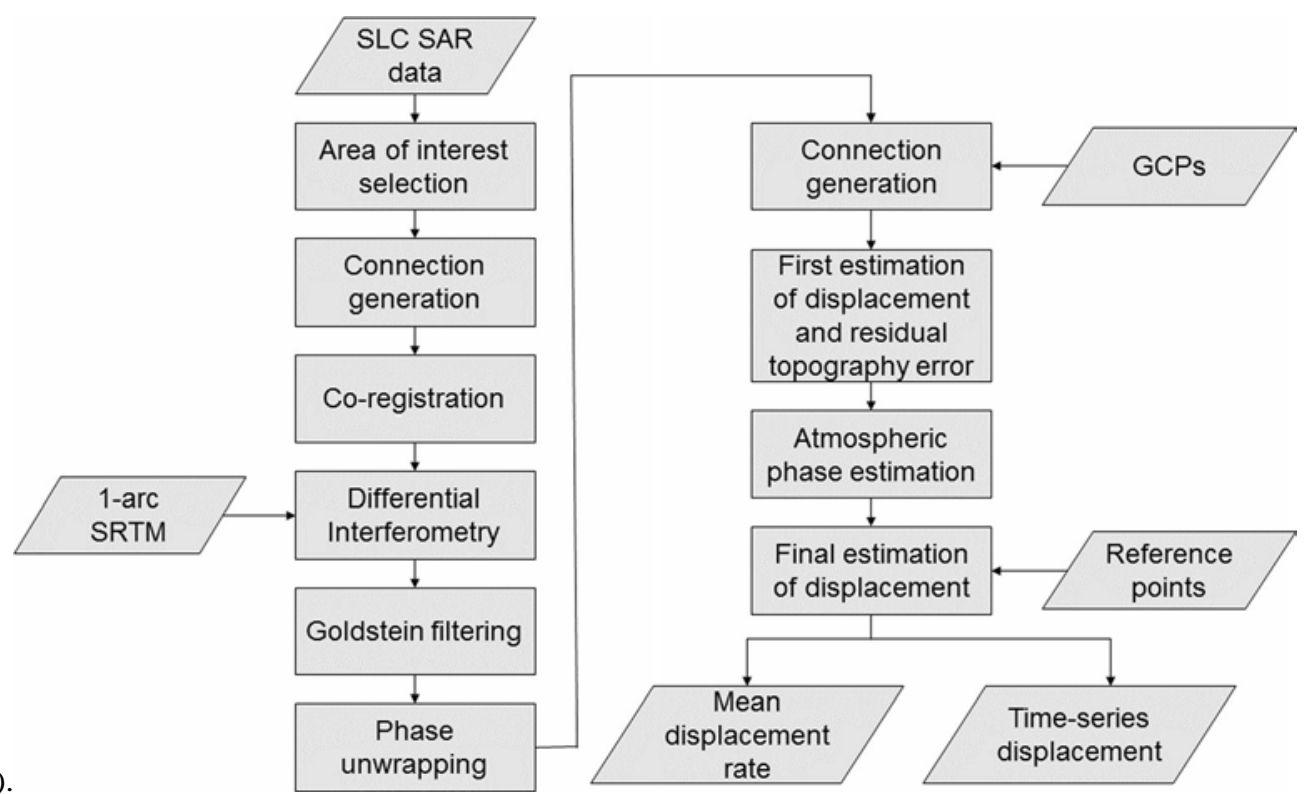

Fig. 3 Workflow of time series InSAR processing of Single Look Complex (SLC) products of ALOS PALSAR data. GCPs indicates ground control points

Figure 3 shows the flow chart outlining the procedure of SBAS for detecting ground deformation along line of sight (LOS) direction. All the SAR images were co-registered and 52 interferograms were generated with a perpendicular baseline threshold of $3700 \mathrm{~m}$ and a temporal baseline of 365 days (Fig. 4). A multi-look of $1 \times 5$ in range and azimuth direction, respectively, in addition to the Goldstein filter method (Goldstein and Werner 1998), was used to increase the signal-to-noise ratio and the coherence within the interferograms. As the phase in the interferograms is wrapped between $-2 \pi$ and $2 \pi$, the phase of coherent targets (CTs) was unwrapped with the minimum cost flow (MCF) algorithm (Costantini 1998; Pepe and Lanari 2006). Some pairs with average low coherence and unwrapped phase errors in our study area were discarded. Interferometric coherence represents the magnitude of the cross-correlation coefficient between two coregistered complex images. The residual phase content and phase ramps were calculated to correct the unwrapped phase by selecting and refining stable ground control points 
(GCPs). All GCPs (mainly buildings in the valley floor) were selected in flat and stable area based on the experience of field survey and understanding of interferograms. The preliminary displacements were estimated using a linear model, and residual topography was also removed. Finally, the atmospheric signal phase was observed and removed from the original displacement component with a high-pass temporal filter and a low-pass spatial filter. For the application of the InSAR time series, the final deformation result should be based on the reference point where the absolute velocity is deemed to be zero. Since there is no ground truth observation in our study area, a reference point was selected using the following criteria to ensure the reliability of the retrieved deformations: it is located on buildings in a flat area of the main valley floor (i) where field observations confirm that the point does not exhibit clear deformation (ii).

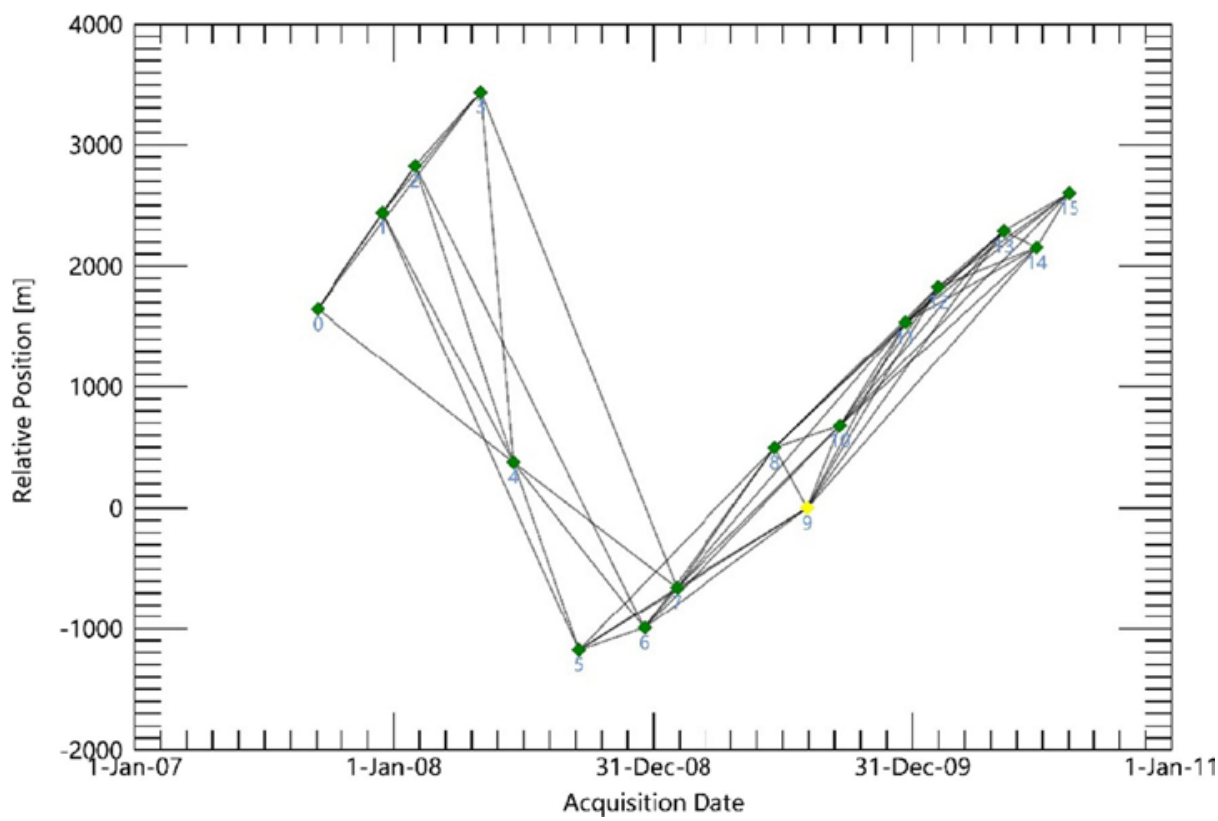

Fig. 4 Spatial-temporal distribution of interferogram formation. Green dots and black lines represent images and interferometric pairs, respectively. Yellow dot is the master images used for the co-registration

After processing the InSAR time series in SARscape, the LOS displacement rates ( $V_{\text {LOS }}$ ) were projected along the steepest slope direction ( $V_{\text {slope }}$ ) using the formula in Zhao et al. (2012) and Cigna et al. (2013). As the ratio between $V_{\text {LOS }}$ and $V_{\text {slope }}$ could tend to zero (which could induce anomalous solutions) due to DTM inaccuracies, the values between 0 and 0.3 were rounded to 0.3 , and the values between 0 and -0.3 were rounded to -0.3 . Positive values in $V_{\text {slope }}$ indicate movement uphill, while negative values indicate movement downhill.

\section{Results and analysis}

\subsection{InSAR displacement rates}

The mean velocity map obtained from the ascending ALOS PALSAR datasets is illustrated in Fig. 5a. The surface displacement rates are extracted for points with a temporal coherence threshold $\geq 0.6$. The coherence threshold (CT) was selected using two criteria: (1) low geometrical and temporal coherence due to the high relief, seasonal vegetation coverage, and quick movements of landslides and (2) assurance of a sufficient 
pixel density. A total of 80,010 detected CTs cover the clipped SAR image (approximate area $436 \mathrm{~km}^{2}$ ) providing an average density of 378 CTs $\mathrm{km}^{-2}$. The density of detected CTs for the L-band data is three times greater than using C-band data processed in Zhang et al. (2016). The displacement was extracted along the Line-Of-Sight (LOS) of the satellite with an angle of $23.3^{\circ}$ from the vertical at the centre of the scene. Negative values represent ground motion away from the satellite, while positive values represent movement towards the satellite. The CTs were mostly located on the westward and eastward slopes with a slope angle below $52.3^{\circ}$ due to radar shadow and layover phenomena. The InSAR results show high consistency with the geometric distortion results. Deeply incised valleys and steep escarpments show an absence of CTs, with a correspondingly low R-index values and topographic distortions (Fig. 2).
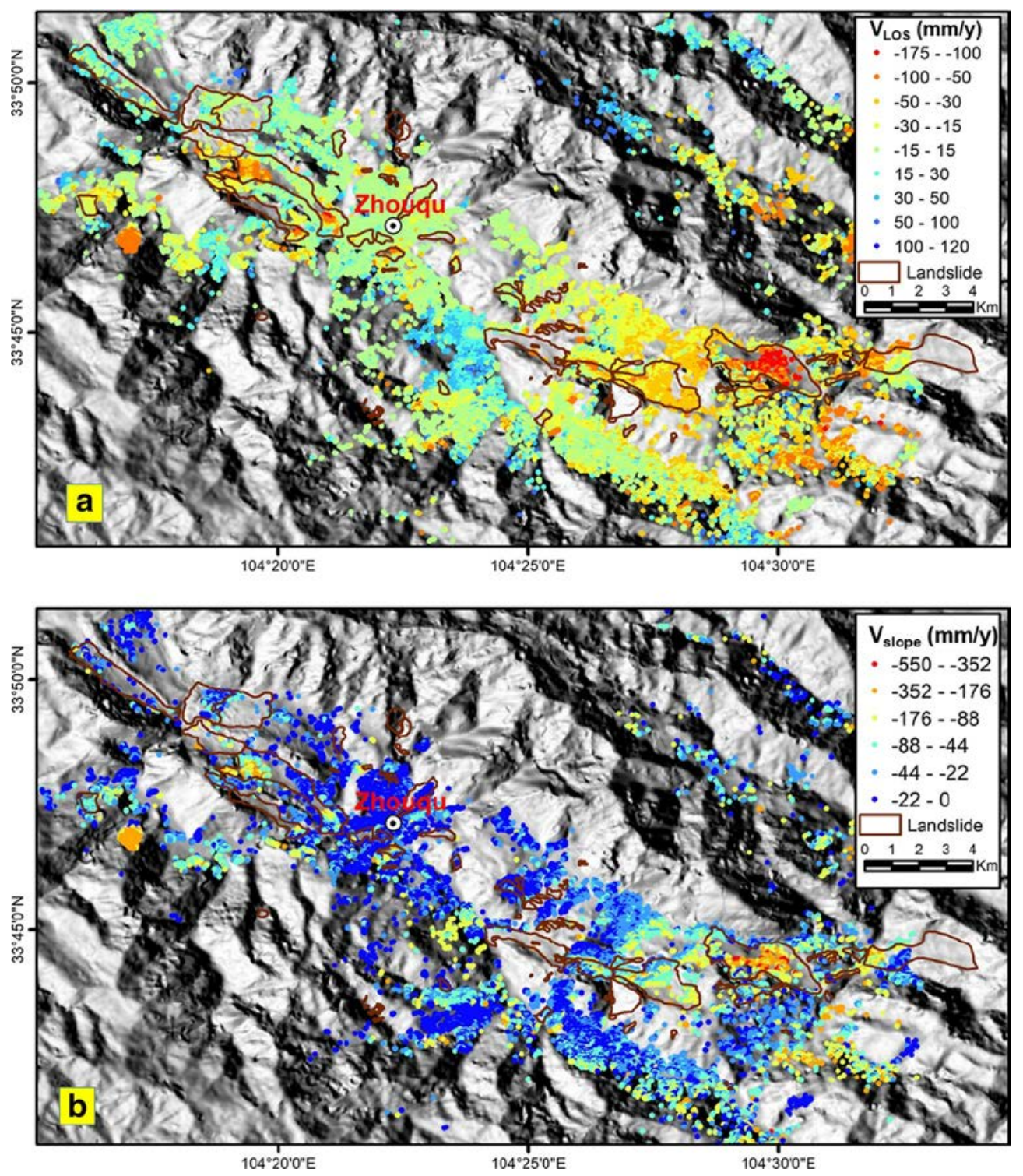

Fig. 5 Displacement rate map along LOS (a) and the steepest slope (b) derived by SBAS technique from ALOS PALSAR data plotted in shaded relief over Zhouqu region 
In the Zhouqu region, displacement rates between 120 and - $175 \mathrm{~mm} /$ year were detected along the LOS direction ( $V_{\text {LOS }}$ ) (Fig. 5a). Both positive and negative displacements could be found in different sections of slopes. Most of the highest deformation rates occurred in or around areas affected by landslides with many earthflows (e.g., Suoertou, Daxiaowan, Zhenjie, Shijiashan, Zhongpai, Liaodong, and Huama) showing displacement rates over 100 mm/year (Fig. 5a). According to Chen et al. (2013) and Schlögel et al. (2015), the downslope deformations on moderately steep sections (slope angle $<37.7^{\circ}$ ) of slopes facing the satellite could show as an uplift along the LOS. Therefore, even positive $V_{\text {LOS }}$ could still represent downslope deformation in these types of slopes. Displacements along the steeper slope direction $\left(V_{\text {slope }}\right)$ provide a more direct indication of slope deformation (Fig. 5b).

Deformations with $V_{\text {slope }}>500 \mathrm{~mm}$ /year were detected. Coinciding with displacements along the LOS, most of large $V_{\text {slope }}(>200 \mathrm{~mm} /$ year) occurred in or around the area influenced by landslides, especially in earthflows (Figs. 1 and 5b). However, $V_{\text {slope }}>200 \mathrm{~mm} /$ year was also found in some slopes that were outside of the mapped landslide polygons and this has helped to update the landslide inventory. In addition, $V_{\text {slope }}$ of around $100 \mathrm{~mm} / \mathrm{year}$ was found in some small valleys, gullies, and gentle slopes. These deformations might be the result of erosion, rock weathering, debris movement (e.g., rockfall or collapsible anthropogenic deposits, etc.), and deformation in poorly constructed buildings that is not ground related.

A coherence-based method was used to estimate precision measurement.

$$
\text { Precision }=\sqrt{\frac{1-\gamma^{2}}{2 \gamma^{2}}} \times \frac{\lambda}{4 \pi}
$$

where $\gamma$ is the interferometric coherence, and $\lambda$ is the wavelength of the L-band ALOS PALSAR sensor (23.5 $\mathrm{cm})$. Since the calculated precision is a positive value, the negative value of displacement rates was multiplied by -1 to compare with precision results. Figure 6 shows the distribution of the precision combined with absolute value of displacement rates. The points to the right of the red line indicate displacement rates that are larger than the precision values, implying that these points are reliable. Based on the density analysis of precision, we found that the $30 \mathrm{~mm} /$ year is at an $80 \%$ confidence level (Fig. 6). It can be seen that pixels with displacement rates over $30 \mathrm{~mm}$ /year form a reasonable minimum threshold.

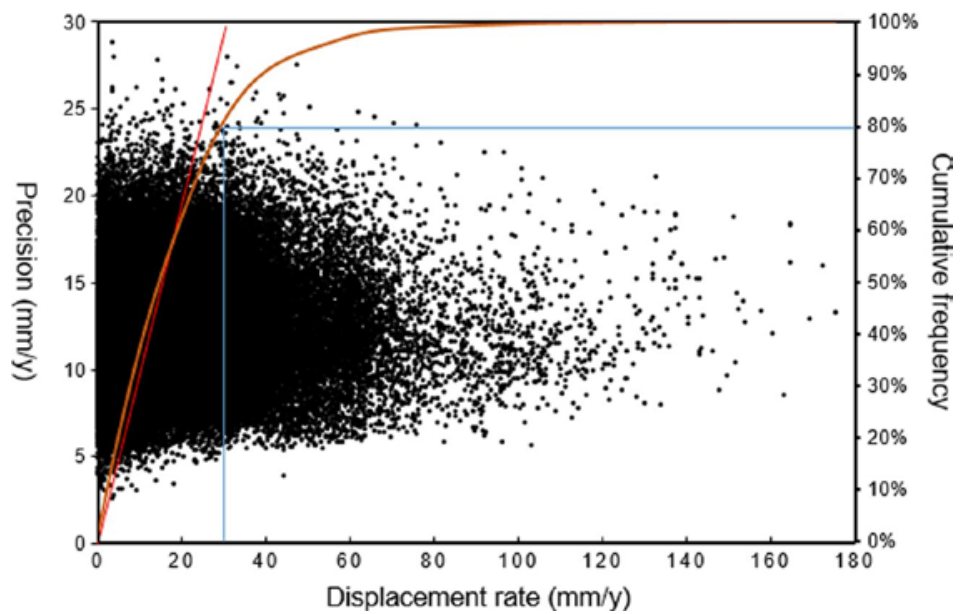

Fig. 6 Comparison of estimated displacement rates precision computed based on coherence. The red line represents the same value between displacement rate and precision. Blue line represents the displacement rates equal to $30 \mathrm{~mm} / \mathrm{year}$ at $80 \%$ 
confidence level

\subsection{Landslide CT coverage and activity evaluation}

Several previous studies assessed the state of activity of landslides by calculating the average $V_{\text {slope }}$ of the landslides that contains sufficient number of CTs and defined the $V_{\text {slope }}$ stability threshold statistically (Colesanti and Wasowski 2006; Meisina et al. 2008; Notti et al. 2010; Cigna et al. 2013; Herrera et al. 2013; Bonì et al. 2016). The $V_{\text {slope }}$ stability threshold for our study area was calculated to be $-43.6 \mathrm{~mm} / \mathrm{year}$. This value was obtained by averaging two indicators: the $V_{\text {slope }}$ standard deviation $\left(-42.9 \mathrm{~mm} / \mathrm{year}\right.$; cf. Bonì et al. 2016) and the $V_{\text {slope }}$ value representing $68 \%$ of the CT population ( $-44.3 \mathrm{~mm} /$ year; cf. Herrera et al. 2013). To identify an active landslide, the polygon should contain at least three CTs exceeding this threshold. Based on above criterion, 20 new slopes were classified as landslides that were not previously mapped in the landslide inventory.

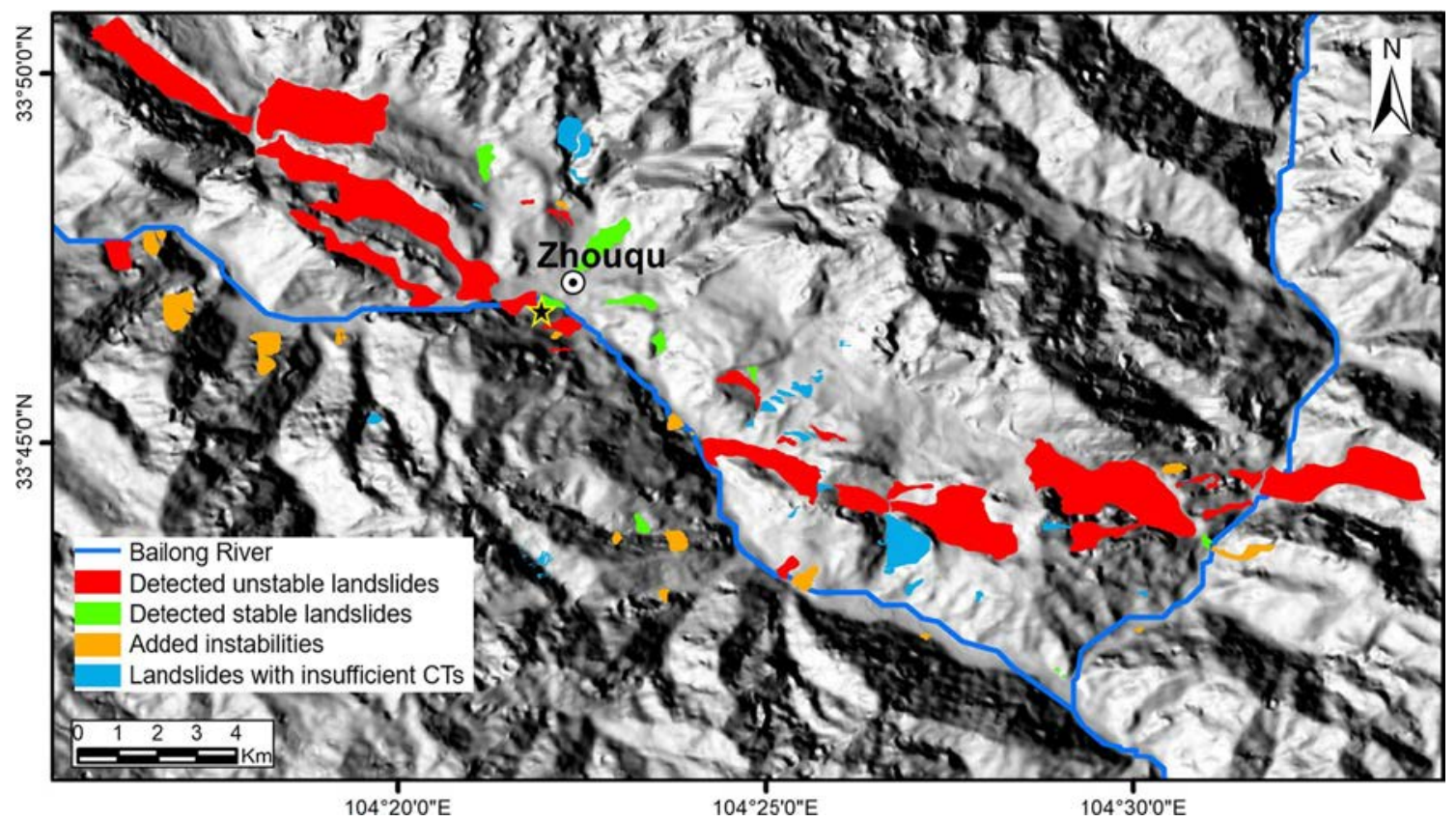

Fig. 7 Landslides classified by the detection capacity of InSAR results. The black star with yellow outline indicates the location of the rainfall station

Table 1 Number and displacement rates of detected landslides with sufficient CTs. No. of CTs/landslide indicates the average number of CTs in each landslide. Vslopemax and Vslopemean indicate the maximum and mean displacement rate of each type of landslides number of CTs in each landslide. Vslopemax and Vslopemean indicate the maximum and mean displacement rate of each type of landslides

\begin{tabular}{cccccccc}
\hline & Mapped & Detected & $\begin{array}{l}\text { Instability } \\
\text { detected }\end{array}$ & $\begin{array}{c}\text { Instability } \\
\text { added }\end{array}$ & $\begin{array}{c}\text { No. CTs } \\
\text { llandslide }\end{array}$ & $\begin{array}{l}\mathrm{V}_{\text {slope }} \text { max } \\
(\mathrm{mm} / \mathrm{y})\end{array}$ & $\begin{array}{l}\mathrm{V}_{\text {slope }} \text { mean } \\
(\mathrm{mm} / \mathrm{y})\end{array}$ \\
\hline Earthflows & 11 & 11 & 11 & 0 & 485 & -550 & -71 \\
Other landslides & 69 & 25 & 15 & 20 & 92 & -307 & -65 \\
\hline
\end{tabular}

The statistical results and landslide detection capacity are summarized in Table 1 and Fig. 7. The comparison of the 
spatial distribution of the InSAR results, with the 80 inventoried landslides, reveals that velocity mapping detected 11 (100\%) of the earthflows and 25 (36\%) of the other types of landslides within sufficient CTs, which represent $45 \%$ of mapped landslides. The results suggest that 11 earthflows and 15 other landslides are unstable, which comprise 38\% of mapped landslides and $72 \%$ of detected landslides. The additional 20 landslide polygons were added to the landslides inventory map.

The large area and gentle slope gradient of the earthflows generally allowed detection of many CTs in each landslide body, with the exception of the Xieliupo earthflow, where the displacement rates exceed the monitoring ability of the InSAR technique (Fig. 8). Compared to other types of landslides, earthflows showed faster $V_{\text {slop }}$ max and $V_{\text {slop }}$ mean during 2007 and 2010.
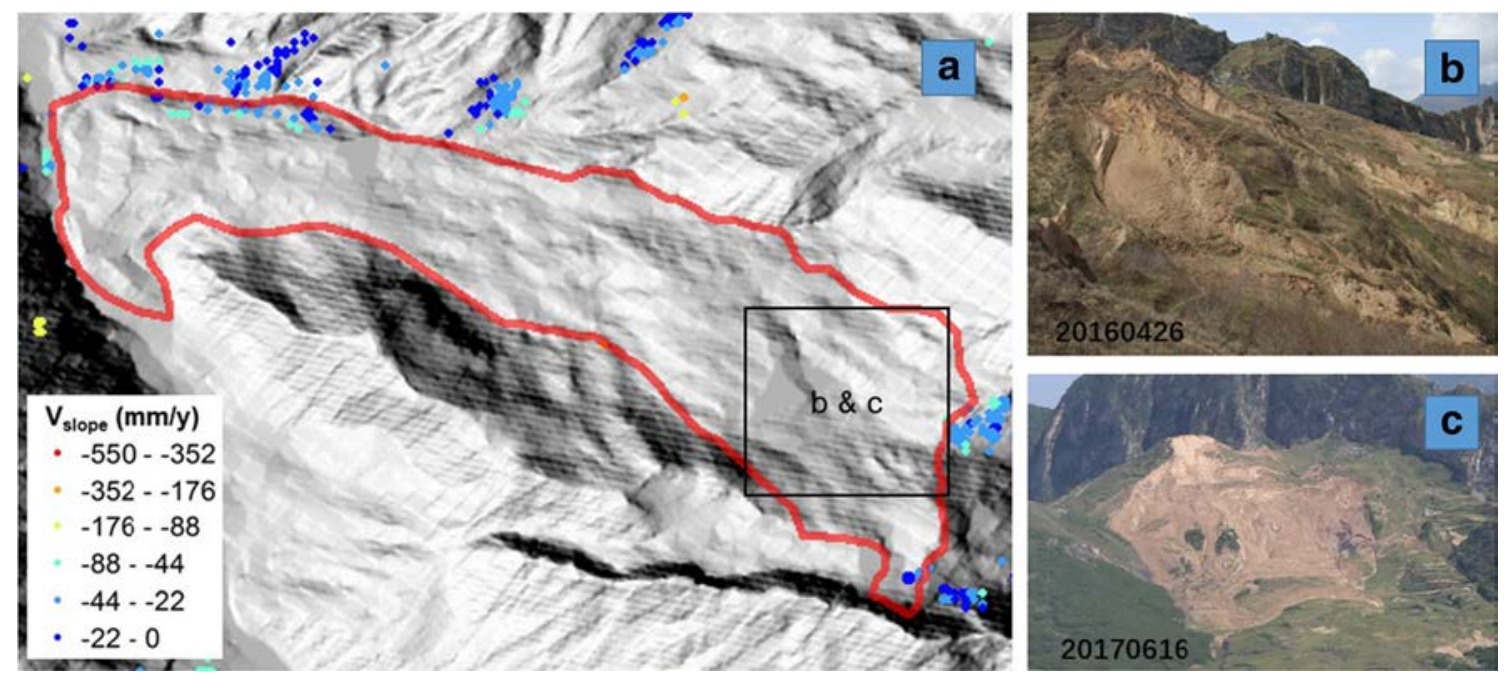

Fig. 8 Movements of Xieliupo landslide exceed the InSAR detection limits. a InSAR results over Xieliupo landslide. b, c Photographs of the upper section of Xieliupo landslide taken on March 26, 2016 and June 16, 2017

Table 2 Characteristics of earthflows

\begin{tabular}{llllllllc}
\hline \multicolumn{1}{c}{ Name } & \multicolumn{1}{c}{$\begin{array}{c}\text { Dominant } \\
\text { Bedrock }\end{array}$} & $\begin{array}{c}\text { Area } \\
\left(\mathrm{km}^{2}\right)\end{array}$ & $\begin{array}{c}\text { Length } \\
(\mathrm{m})\end{array}$ & $\begin{array}{c}\text { Maximum } \\
\text { Width } \\
(\mathrm{m})\end{array}$ & $\begin{array}{c}\text { Relief } \\
(\mathrm{m})\end{array}$ & $\begin{array}{c}\text { Mean } \\
\text { slope } \\
\left({ }^{\circ}\right)\end{array}$ & $\begin{array}{c}\text { Mean } \\
\mathrm{V}_{\text {slope }} \\
(\mathrm{mm} / \mathrm{y})\end{array}$ \\
\hline Yading & Slate, Phyllite & 3.21 & 2680 & 1530 & 536 & 13.7 & -25 \\
Suoertou & Limestone, Slate & 3.17 & 4560 & 1160 & 1075 & 14.7 & -67 \\
Zhenjie & Slate, Phyllite & 0.54 & 1300 & 625 & 263 & 15.1 & -94 \\
Shijiashan & Slate, Limestone & 2.48 & 2930 & 1625 & 552 & 15.3 & -61 \\
Zhongpai & Slate, Limestone & 3.95 & 4040 & 1380 & 905 & 15.5 & -124 \\
Wutanshan & Slate, Phyllite & 2.27 & 4120 & 710 & 862 & 15.8 & -31 \\
Jingbian & Limestone, Slate & 1.09 & 1830 & 790 & 432 & 15.9 & -60 \\
Huama & Limestone & 2.78 & 3440 & 1030 & 932 & 16.7 & -82 \\
Xieliupo & Slate, Phyllite & 1.46 & 2700 & 830 & 870 & 17.2 & -27 \\
Liaodong & Limestone & 0.58 & 1770 & 710 & 530 & 21.3 & -59 \\
Daxiaowan & Limestone & 1.21 & 3800 & 470 & 1163 & 21.5 & -52 \\
\hline
\end{tabular}

\subsection{Controls and impacts of earthflow movements}


With the large coverage and faster movement, the 11 earthflows in the Zhouqu region involve entire slope segments from the local erosion base to the top of the local catchment and have characteristic displacement rates of the order of 10 to $10^{3} \mathrm{~mm} /$ year(Yang etal. 2013; Wasowski and Bovenga 2014; Zhang et al. 2016; Jiang et al. 2016). These earthflows move over a complex set of basal slip surfaces where ongoing deformation of the landslide body is accommodated by multiple internal shear surfaces and viscous deformation (Yang et al. 2013; Hungr et al. 2014). The composition of earthflow bodies comprises the main local weak rock lithologies (dominated by slates and phyllites) and a cover of loess and fractured rock. The basal slip surface depth varies from 8 to $50 \mathrm{~m}$ (Huang et al. 2013; Yang et al. 2013; Jiang et al. 2016).

We analyzed the controls of movement of these earthflows by combining the characteristics of earthflows with displacements identified by the InSAR technique and the main lithology (Table 2). The lower slope gradients of earthflows suggest that on average residual shear strength values (effective angles of internal friction) are likely to be lower than approximately $13^{\circ}$ to $15^{\circ}$. However, no apparent correlation between shape, relief, and mean displacement rates was observed.

There appears to be a correlation between the movement rates and the complexity of the fault system. Earthflows with larger displacement rates, such as at Zhongpai, Zhenjie, Huama, and Shijiashan, are concentrated near the confluence of the Bailong River and the Min River, where many faults intersect each other (Fig. 1). High fault density and complexity indicate greater fracturing of the bedrock, and combined with a steeper topography following local incision, this would provide suitable predisposing conditions for landslide movements with greater displacement rates. The distribution of earthflows shows a regional linear clustering controlled by the Zhouqu and PH active faults. Major faults crossing these earthflows also strongly affect their morphology resulting in a trough-like shape where side scarps are generally very well developed and fault controlled. However, in most cases, an obvious back scarp is missing.

With respect to the orogenic evolution, the Bailong River basin is located between the mainly left-lateral strikeslip faults (the west Qingling fault and the east Kunlun fault), which transfers stress from the east Kunlun fault to the west Qingling fault, controlled and influenced by uplift and compression to northeast of Qinghai- Tibet plateau (Dewey and Burke 1973; Van Der Woerd et al. 2002; Molnar and Stock 2009; Kirby and Harkins 2013; Bi et al. 2016; Zheng et al. 2016). As response to compression and uplift, the Bailong River has incised more than 140 m during the Quaternary (Yuet al. 2012) exploiting geological weaknesses including the fault-controlled belt of lowgrade metamorphic rocks (e.g., slates, phyllites). This led to a cascade of erosional/denudational processes in the form of deeply incised gullies and the increase of relative relief/gravitational energy contributing to the long-term development of large-scale, slow-moving landslides. In addition, the uplifting ridges and incising valley bottom constrain the head and toe of these earthflows.

The earthflow movements have the capability to significantly affect regional topography. The impacts of earthflows can be observed by comparing the distribution of slope gradients inside the landslide polygons with that of a zone immediately surrounding the polygon (Agliardi et al. 2013; Crosta et al. 2013) (Fig. 9). This difference in slope gradient characteristic was analyzed for the 11 large earthflows using a buffer of $0.5 \mathrm{~km}$. The slope distribution results show significant reduction in slope gradient $\left(14^{\circ}\right)$ inside the earthflows compared to the adjacent areas $\left(18^{\circ}\right.$; Fig. 9). The lower slope gradient and the large areas covered by the earthflows illustrate the effect that these landslides have on the morphology of the landscape of this region, generally reducing slope angles and flattening relative relief. In the long term, the movement of these earthflows results in a local relief with characteristic slope angles of less than $13^{\circ}$ controlled by an equilibrium between available shearing resistance and precipitationinduced pore pressure variations coupled with additional stresses induced by periodic seismic acceleration resulting 
from regional earthquake activity. Over time, the elevation differences between the landslide body and the adjacent ridges will increase and the linear clustering of these landslides is therefore likely to further develop into a large elongated trench that can be further exploited by fluvial erosion of the Bailong River.

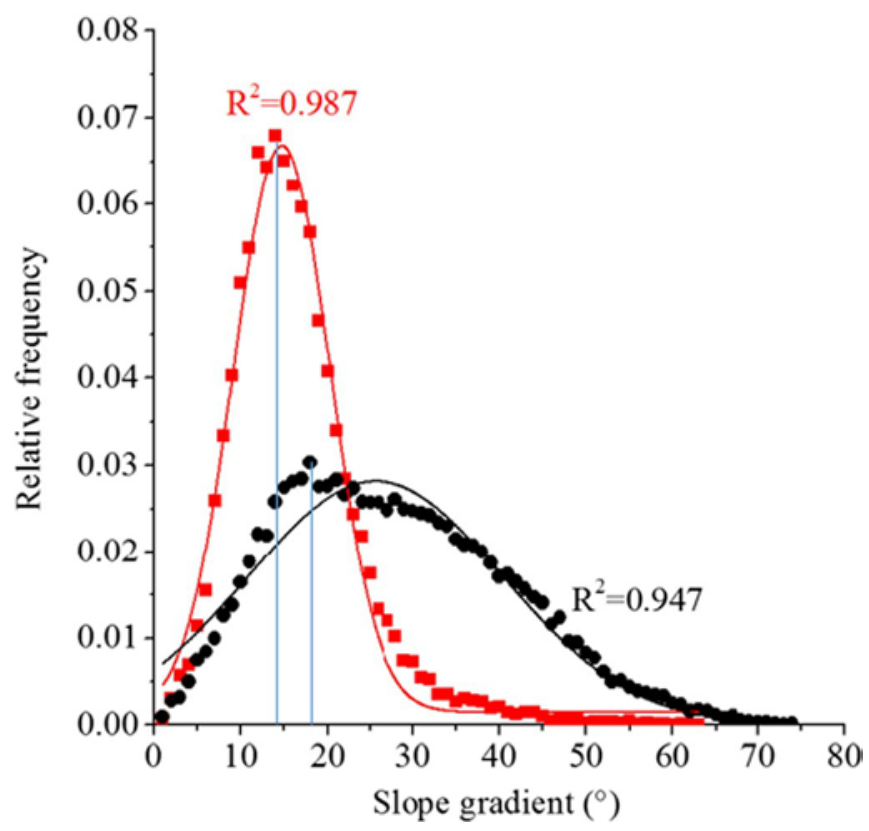

Fig. 9 Relative frequency distributions of slope angle; all values were computed from the DTM inside earthflows area (red rectangle) and in neighboring areas within $0.5 \mathrm{~km}$ buffers (black circles). The distributions of slope angle were fitted by Gaussian distribution functions (line)

\section{The Suoertou landslide}

The Suoertou landslide, located to the west of Zhouqu County town, is a large earthflow intersected by the Zhouqu fault. This complex earthflow comprises one major flow body and six secondary small slides that contribute materials onto the main flow (Fig. 10). The head scarp of the earthflow is absent as it forms a watershed with an adjacent large earthflow, while the side scarps are interacting with the fault scarps. The bedrock not only is characterized as shales, slates, and phyllites, but also contains sections where limestone is carried along by the landslide. The landslide has a length of 4.5 $\mathrm{km}$, and widths range from 120 to $400 \mathrm{~m}$ with an area exceeding $3 \mathrm{~km}^{2}$. It is estimated that the average thickness of the landslide is $\sim 65 \mathrm{~m}$ with a volume of approximately $80 \times 10^{6} \mathrm{~m}^{3}$ (Huang et al. 2013). The current elevation difference from top to toe is approximately $900 \mathrm{~m}$. Monitoring data from ground-based instruments and InSAR techniques provide a record of displacement since2000(Huangetal.2013;WasowskiandBovenga2014;Zhangetal. 2016). In addition, there is a rainfall station close to this earthflow, providing sufficient precipitation records to analyze the potential correlation with the time series displacements (Fig. 7).

This earthflow poses a serious threat to more than 2000 people living on the landslide body. Moreover, this landslide has the potential to block the Bailong River, destroy the hydropower station, and generate floods and secondary geohazards to the Zhouqu County town, which is less than 1 km downstream. 

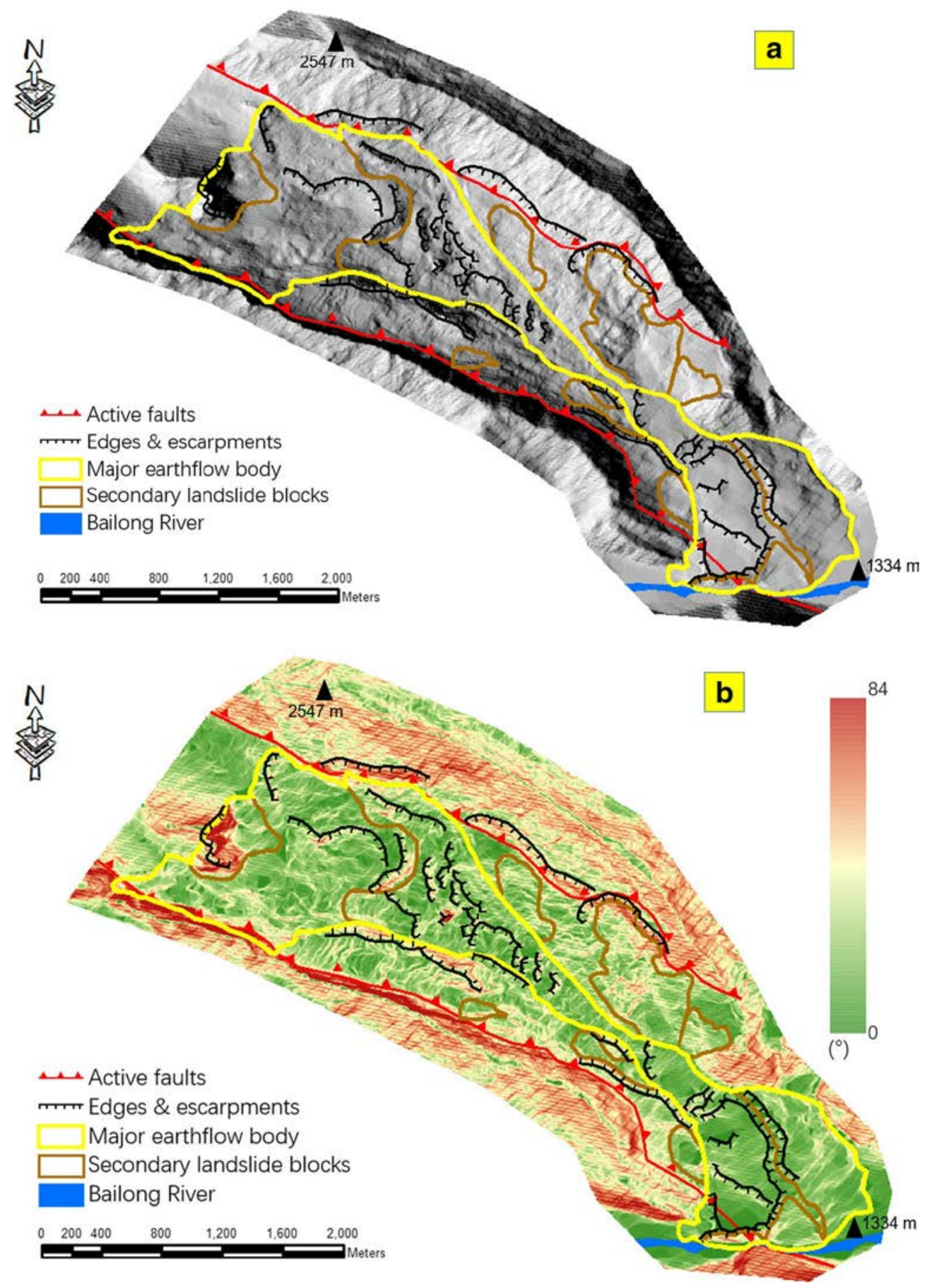

Fig. 10 Suoertou earthflow complex. a Shaded relief map of Suoertou earthflow complex. b Slope map

Figure 11 shows the mean displacement rates map of Suoertou earthflow converted into the steepest slope direction (the negative values indicate downslope movement). Combined with the initial geomorphological mapping, the spatial deformation patterns of the earthflow are revealed. The SE aspect and lower slope angle (about $12^{\circ}$ ) aid the detection of CTs of the ascending orbit ALOS PALSAR satellites. Overall, the average of 
more than 1600 CTs covering the Suoertou earthflow provides an indication of downslope movement of 67 $\mathrm{mm}$ /year. However, significantly greater velocities of up to $370 \mathrm{~mm} /$ year were measured on the upper and lower portions of the earthflow. The large movements on the upper portion correspond to highly fractured surfaces covered by many local slides, rock flows, rockfalls, and collapses (Fig. 14a). In addition, the upper portion is split into two parts by a SWtrending escarpment, which differentiates an unstable (south) and stable sector (north). There are no CTs in middle portion of major earthflow body, which is most likely the result of displacement velocities that exceed the thresholds of the InSAR technique. The variations of deformation velocity in the lower portion are consistent with the location of edges and escarpments. The northeastern part of the lower earthflow is relatively stable compared to central/southwestern parts. The village of Suoertou is located in this more active part where deformation velocities of more than $300 \mathrm{~mm} /$ year have been measured. In an attempt to stabilize this part of the earthflow, an integrated set of works has been carried out that include anchored retaining walls and piles (Fig. 14c-e).

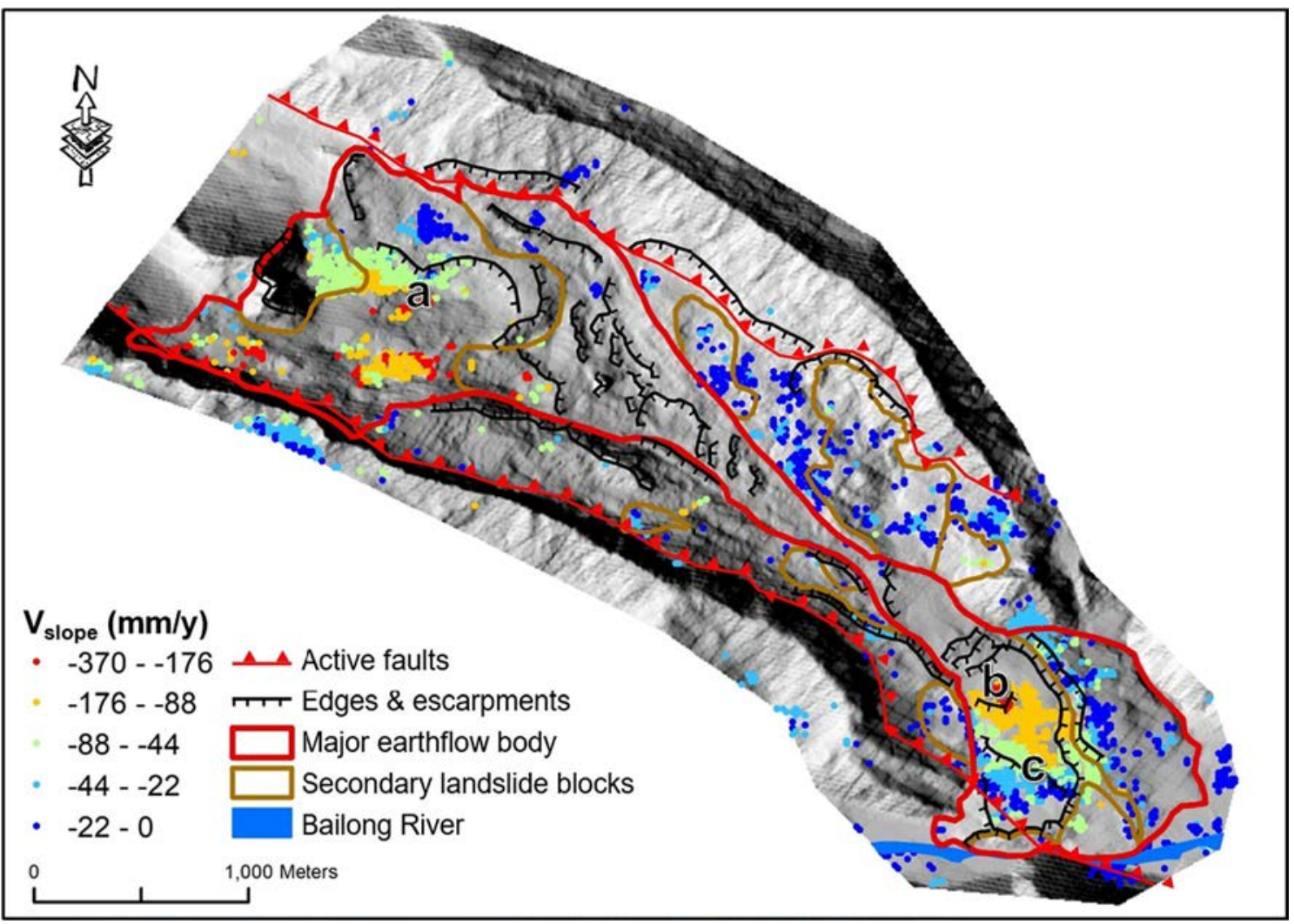

Fig. 11 Displacement rate map along the steepest slope of the Suoertou earthflow. The labels (a, b) indicate the location of time series displacements in Fig. 15

To balance the InSAR coverage and reveal the spatial patterns of earthflow deformation, a series of deformation maps was generated at a lower coherence threshold of 0.35 . However, the deformations of the Suoertou earthflow associated with long-duration ( $>46$ days) interferograms exceed the phase-change threshold, which induces decorrelations or unwrapping errors in the InSAR results (Stimely 2009; Handwerger et al. 2015). This was observed for the central section of main earthflow (Fig. 11). Therefore, the two best 
interferograms were processed with a larger filtering window size (96 or 128) to solve the problems with the phase jump in a few unwrapped interferograms, and this assisted with the interpretation of the spatial pattern of earthflow deformation.

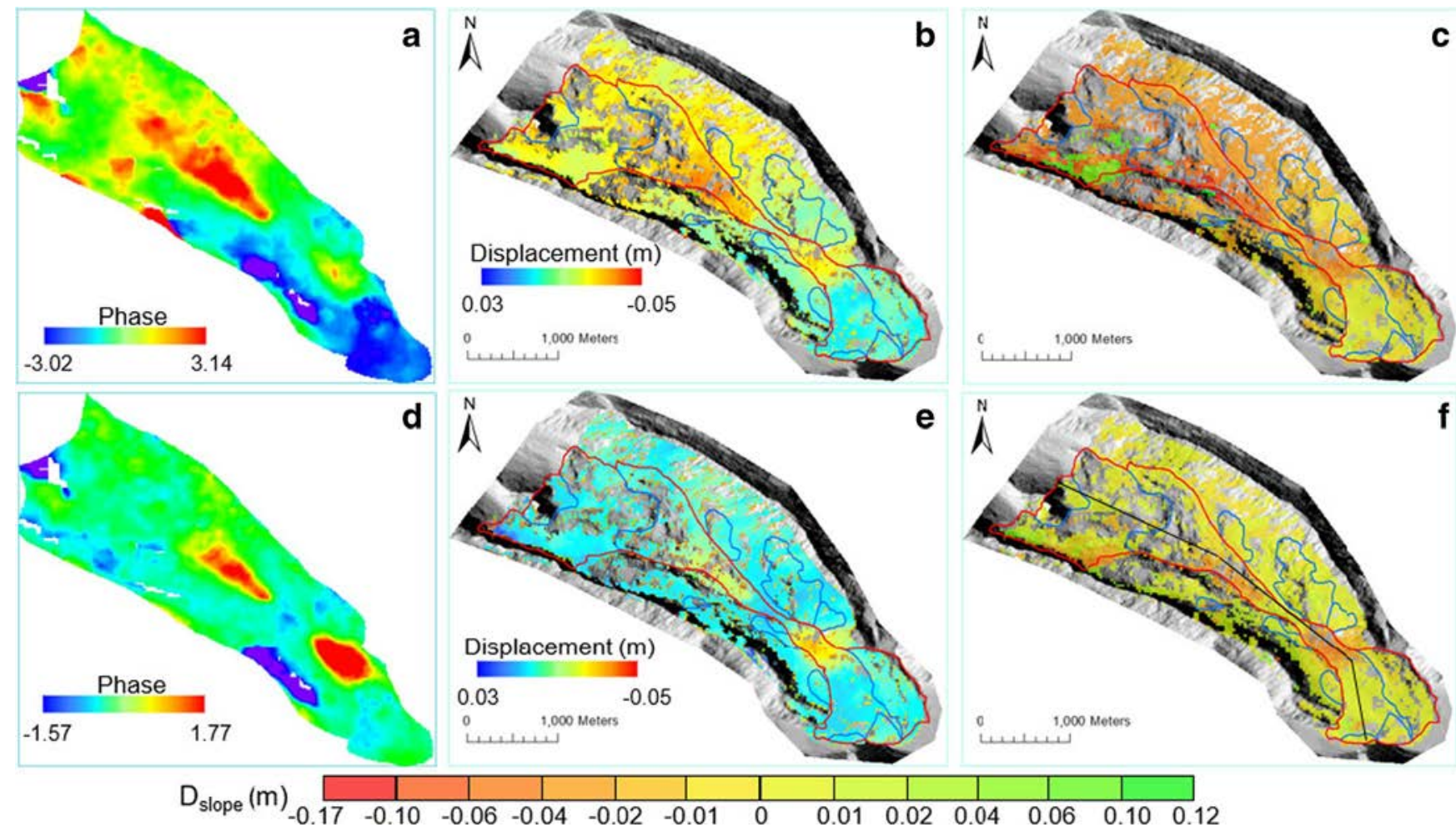

Fig. 12 Interferograms and displacements of Suoertou earthflow. a-c The filtered interferogram, LOS displacements, and the steepest slope displacement (Dslope) for the period August 5, 2009-September 20, 2009. d-f The filtered interferogram, LOS displacements, and the steepest slope displacement (Dslope) for the period December 21, 2009-February 5, 2009. a, d In SAR geometry. The black line in $\mathrm{f}$ indicates the location of profiles for Dslope and geology in Fig. 13. The color bar in the bottom indicate the changes of movements of $\mathrm{c}$ and $\mathrm{f}$

Figure 12 shows the displacement results of two interferograms in summer (August 5, 2009-September 20, 2009) and winter (December 21, 2009-February 5, 2009). Because of short temporal (46) and spatial ( $<700 \mathrm{~m}$ ) baselines, most of the earthflow area is correlated. Both interferograms are considered of good quality because more than $90 \%$ of the phase values are unwrapped, and no phase jump is observed. As these two interferograms were selected before the final displacements inversion in the SBAS process, the errors induced by residual topography phase and atmospheric effects have been removed. For the purpose of classifying the motion zones, we generated and analyzed the profile of displacement associated with geological profiles of thelandslide(Fig. 13).

The deformation map and profile of displacements generated from the interferograms enable segmentation of the major flow body into four zones: an upper transport zone (UT), a middle accumulation zone (MA), a lower transport zone (LT), and a lower toe zone (Toe; Figs. 13 and 14). The displacement data for the two periods shows that (1) the zone of greatest movement is UT and LT, with displacement along slope ( $\left.D_{\text {slope }}\right)$ of more than $10 \mathrm{~cm}$ in summer and $5 \mathrm{~cm}$ in winter; (2) the positive ground motion greater than $1 \mathrm{~cm}$ indicating accumulation was detected in MA in winter while a negative displacement of about 1 to $2 \mathrm{~cm}$ was observed in summer; and (3) the Toe zone has accumulative displacements of approximately $1 \mathrm{~cm}$ both in summer and winter. Comparing these 
four zones with the geological profile of the Suoertou landslide, the variation of motion in the zones follows the variation of the shape of the basal slip surface (Fig. 13). MA is located on a bulge in this surface, and this causes the InSAR results to show a local accumulation in this area. The Toe zone shows a slight accumulation which is likely caused by a gentle reverse of sliding surface due to the engineering interventions in this section (Fig. 14ce). The anomalous deformation signal in Fig. 13 might be the result of a local and rapid accumulation (as in MA) at the top of the Quaternary deposits or a sudden change in the direction of sliding.

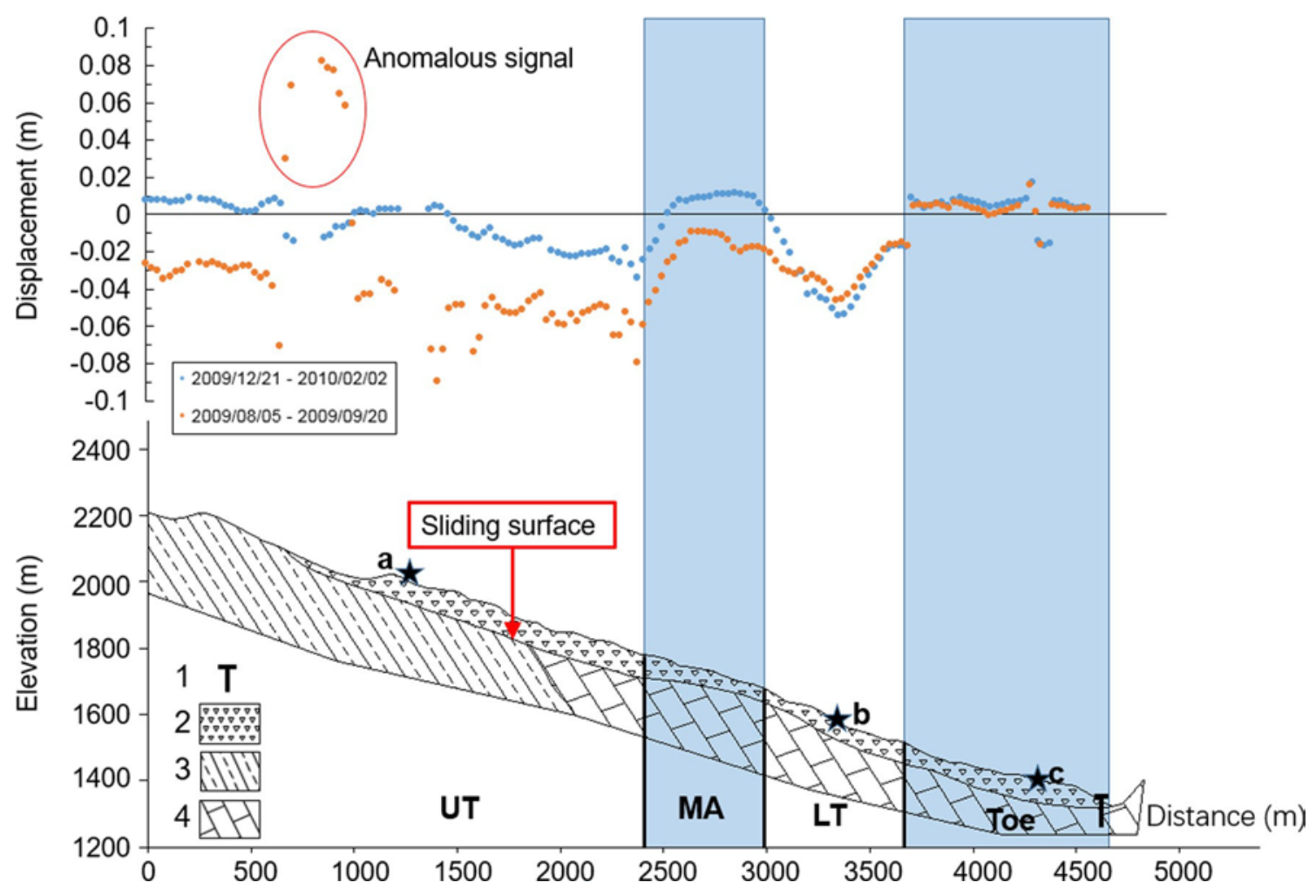

Fig. 13 Detected deformation zones and profile of Suoertou earthflow. Top is the profile of displacement. Bottom is the geological profile of Suoertou earthflow provided by the Geological Environment Monitoring Institute of Gansu Province, China. The location of profile is shown in Fig. 12f. UT, MA, LT, and Toe indicate the upper transport zone (UT), middle accumulation zone (MA), lower transport zone (LT), and lower toe zone (Toe) of the landslide, respectively. The stars indicate the location of generated time series displacement in Fig. 15. (1) anti-slide piles, (2) Quaternary deposits, (3) Devonian slates and phyllites, and (4) Carboniferous limestones

Based on the above analysis, the motion of the earthflow shows clear seasonal kinematic behavior. Significant differences can be observed between the UT and MA zones. The whole upper portion transports material downhill fast and then, where the bulge of the slip surface is located, this appears to slow down in summer, while it is partly stable and accumulating slightly in MA zone in winter. In the LT and Toe zone, similar movements are observed in both summer and winter, showing strong downslope transport in LT and slight accumulation in the Toe zone. The time series displacement curves were analyzed to investigate the possible relationships between the landslide movement, precipitation, and seismic activity. The average daily precipitation is derived from daily records in the Zhouqu station (Fig. 7). To investigate the temporal kinematics of the landslide system, time series displacement 
curves were generated for three zones: UT, LT and Toe (locations are shown in Figs. 11 and 13). Displacements from ten pixels were plotted to show the representative movement of the landslide in each location (Fig. 15). Based on the 3-year InSAR data series, the displacement rate variations show continuous and seasonal movements and high correlation with precipitation. The low dispersion of each acquisition in the UT and LT zones shows consistent movement in each zone. The larger dispersion in the Toe zone could be caused by engineered interventions in this area. Buildings could show different deformations along various directions. In these three zones, UT has the greatest movement while the Toe has the smallest movement.
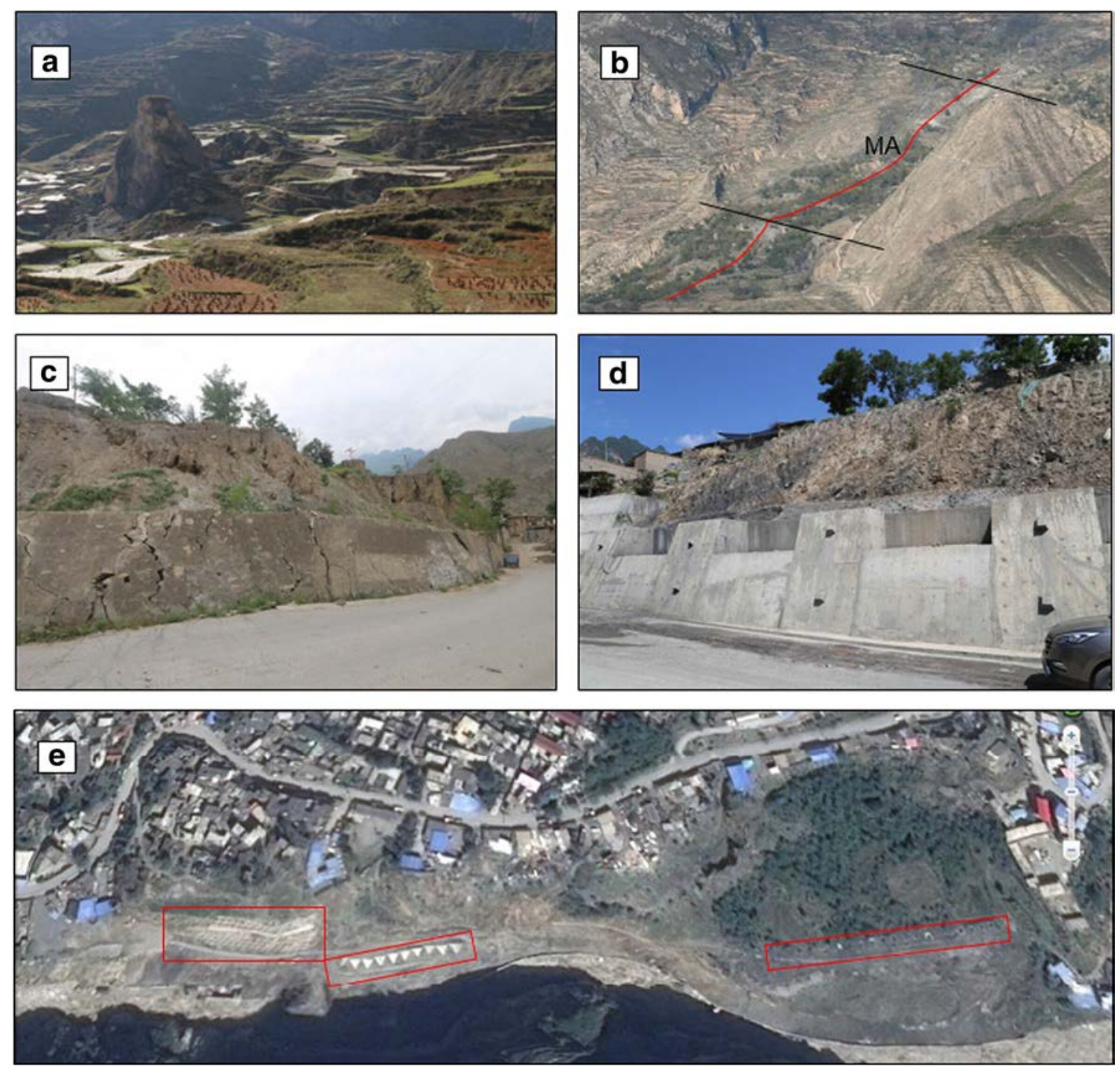

Fig. 14 Photos of Suoertou landslide. a UT zone. b MA zones. c Toe zone. d Anti-slide concrete wall. e Piles in Toe zone. a, b, and c were taken in March 2014. d was taken in June 2017. e is generated from Google Earth image acquired in September 2014. Red rectangles highlight the location of piles 

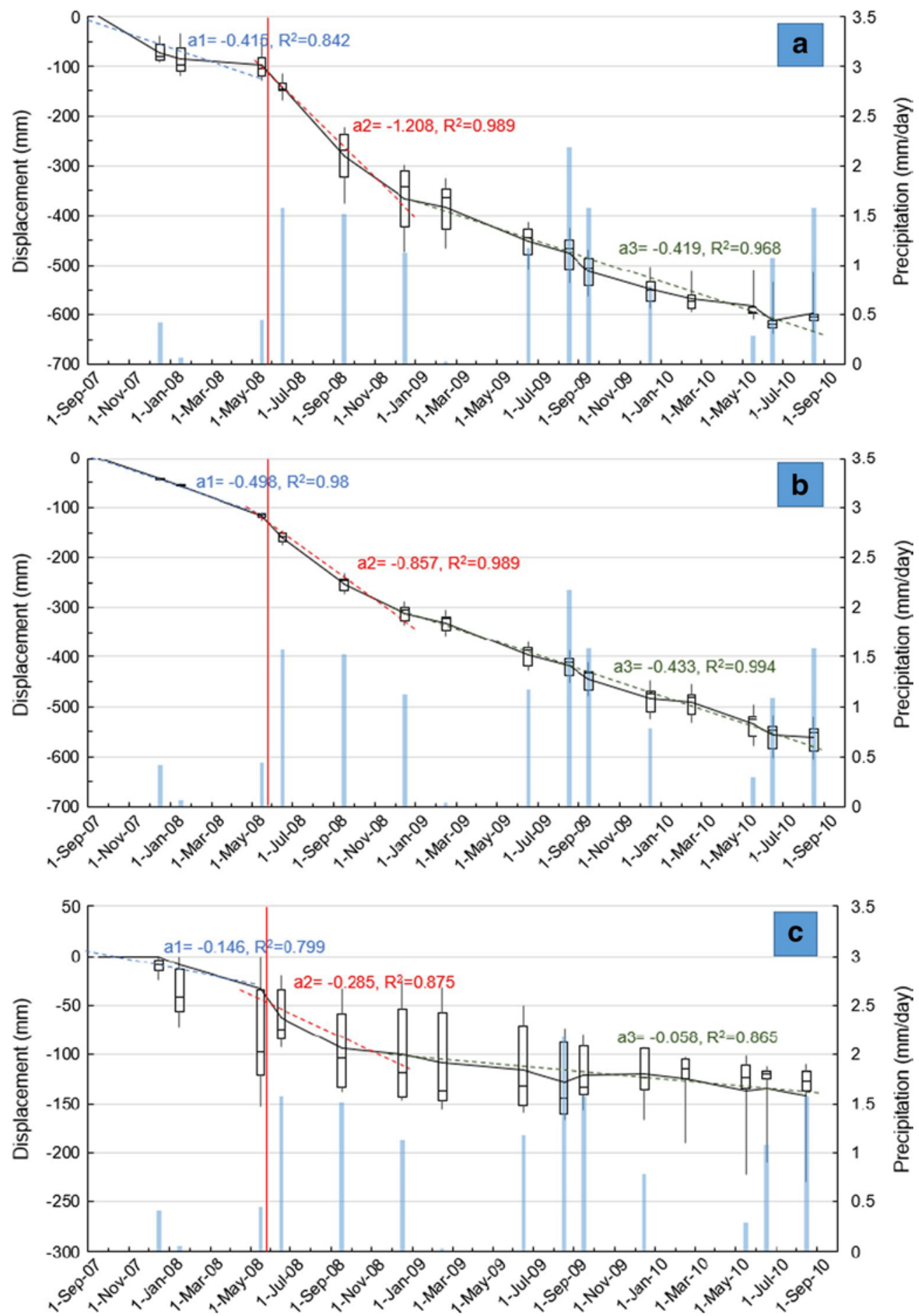

Fig. 15 Box charts of time series displacement of CTs detected in the Suoertou earthflow at location a, b, and c with respect to average daily rainfall for each neighboring acquisition pairs. The lines indicate the linear simulations of average displacement in three periods (pre-acceleration (blue line), acceleration (red line), and postacceleration (green line)). The a1, a2, and a3 indicate the slopes of linear simulation for three periods respectively. The vertical red line highlights the Wenchuan earthquake event

Different displacement rates characterize periods corresponding or following intense rainfalls (Fig. 15). The 
time series show that the sliding motion of the whole earthflow tends to accelerate during the summer rains from May to October. The data show that the acceleration in 2008 is much larger than it was in 2009 and 2010, which is correlated with the Wenchuan seismic event on May 12, 2008 along with exceptionally high rainfall. It is therefore difficult to distinguish and quantify the influence of Wenchuan earthquake, based on these trends. However, the influence period of the earthquake could potentially be observed from the shape of trends in Fig. 15. The time series displacements show a markedly different acceleration period from May to December in 2008 . It suggests that the earthquake's influence lasted for about 6- 7 months. Further interpretation of the trends was carried out by applying simple linear regressions for characteristic segments covering three assumed periods related to the Wenchuan earthquake's influence on landslide stability: (a1) pre-acceleration, (a2) acceleration, and (a3) post-acceleration. In this interpretation it is assumed that the four acquisitions before the earthquake represent the characteristic movement of the landslide. The slopes of linear regressions thus indicate the displacement rates of each period.

Interestingly, the simulation indicates that the displacement rates in post-acceleration period $(-0.433 \mathrm{~mm} / \mathrm{day}$ for LT, $-0.058 \mathrm{~mm} /$ day for Toe) are relatively lower that before the earthquake in the LT ( $-0.498 \mathrm{~mm} / \mathrm{day})$ and Toe zone (-0.146 mm/day; Fig. 15), while a3 ( $-0.419 \mathrm{~mm} /$ day) is slightly larger than a1 $(-0.415 \mathrm{~mm} /$ day) in the UT. Considering the acquisitions before the earthquake are in a dry season, it can be expected that post-acceleration displacement rates would be greater. It is postulated that the earthquake accelerated the release of the energy within the landslide during the acceleration period and that, following this acceleration, the landslide needs to reaccumulate enough material in the UT to enable deformations to progress into the Toe zone (similar to the way a glacier surges). The landslide also shows different accelerations, with the UT zone having the largest acceleration rate $(\mathrm{a} 2-\mathrm{a} 1=-0.783 \mathrm{~mm} / \mathrm{day})$ compared to the $\mathrm{LT}(\mathrm{a} 2-\mathrm{a} 1=-0.359 \mathrm{~mm} /$ day $)$ and the Toe $(\mathrm{a} 2-\mathrm{a} 1=-0.139$ $\mathrm{mm} /$ day).

\section{Conclusion}

This study demonstrates the ability and limitations of the InSAR technique in detecting and monitoring landslides at large scale in the Zhouqu region where a total of 46 instabilities have been mapped. Most of the landslides occur within the Permian limestones, and Devonian limestones and slates, indicating a strong lithologic control on their spatial distribution.

The SBAS technique has been able to detect ground deformation rates over $100 \mathrm{~mm} /$ year by processing 16 ALOS PALSAR images acquired between 2007 and 2010. A multi-disciplinary analysis was applied to identify the predisposing factors of 11 detected earthflows, and statistical analysis was used to identify the contributions of the earthflows on local relief. The conclusions of this study are summarized as follows:

1. The coherent target density and mean displacement rates generated in this high relief area by the SBAS technique from ALOS PALSAR data were far higher than that by SBAS or PSI from ENVISAT data (Wasowski et al. 2014; Zhang et al. 2016). Despite this, the shadow, layover and foreshortening result in the lack of coherent targets for steep areas. The analysis of topographic distortions of SAR data shows that shadow, layover, and foreshortening affect 2.6, 11.8, and 38.8\% of the region, corresponding to 15 , 68.7, and $226 \mathrm{~km}^{2}$ over a total area of $582.3 \mathrm{~km}^{2}$. In total, 80,010 coherent points were extracted, covering an approximate area of $436 \mathrm{~km}^{2}$, that is, 378 coherent points $\mathrm{km}^{-2}$.

2. Spatial distribution of InSAR results provide sufficient CTs for detecting $11(100 \%)$ of the earthflows and 25 
(36\%) of the other types of landslides in the inventory map, which represent $45 \%$ of the total number of mapped landslides. The InSAR deformation analysis helped to determine that 11 earthflows and 15 other landslides are unstable, comprising $38 \%$ of total mapped landslides and $72 \%$ of detected landslides. The final landslide activity map was checked based on the distribution of CTs within each landslide and verified by field survey. In addition, 20 landslides were added based on displacement rates and geomorphological features, which improved the pre-existing landslides inventory map produced by interpretation of optical images and DTMs.

3. In addition to lithological and topographic controls, the distribution of earthflows is also affected by the longterm orogenic evolution and tectonic movements. Earthflows play an effective role in controlling the regional relief towards a dynamic equilibrium of slope gradient controlled by rainfall and tectonic movements.

4. At local scales, the combination of deformation map from InSAR techniques with lithology and morphology allowed the spatial motion patterns of landsliding to be distinguished. The analysis of time series displacements enabled an evaluation of the temporal motion patterns of sliding, which could be established by correlations between displacement variation and precipitation and earthquake events. In the case of the Suoertou earthflow, four motion zones were differentiated based on the deformation map combined with engineering geological observations and geomorphological mapping. The linear simulation of available displacements during three periods (pre-acceleration, acceleration and post-acceleration) reveals that the acceleration from the Wenchuan earthquake may have lasted up to 6-7 months. The earthquake contributed to the release of energy resulting in a temporal acceleration of these earthflows, but following this acceleration, it appears that deformation rates have slowed down and that it will take time for new material to accumulate to stimulate sliding to the extent that was observed before the acceleration period.

\section{Acknowledgements}

The ALOS PLSAR images were provided by the Japan Aerospace Exploration Agency (JAXA). The authors would like to acknowledge V. Banks from BGS for her valuable suggestions to improve the quality of the paper. Colm Jordan, Tom Dijkstra, and Alessandro Novellino publish with permission from the Executive Director of the British Geological Survey, funded by the BGS NERC ODA Programme.

Funding information This study was supported by the Key Technology Research and Development Program of the Ministry of Gansu Province, China (Grant No. 1604FKCA098), the National Natural Science Foundation of China (Grant No. 41661144046), and the National Natural Science Foundation of China (NSFC41702292). This research builds upon initial funding from an Urgency Grant awarded by the Natural Environment Research Council (UK; NE/I016279) and support from the National Natural Science Foundation of China (NSFC 41040005; NSFC41021091). 


\section{References}

Agliardi F, Crosta GB, Frattini P, Malusà MG (2013) Giant non-catastrophic landslides and the long-term exhumation of the European Alps. Earth Planet Sci Lett 365:263-274. https://doi.org/10.1016/j.epsl.2013.01.030

Bai S, Wang J, Zhang Z, Cheng C (2012) Combined landslide susceptibility mapping after Wenchuan earthquake at the Zhouqu segment in the Bailongjiang Basin, China. Catena 99:18-25. https://doi.org/10.1016/j.catena.2012.06.012

Bai S, Xu Q, Wang J, Zhou P (2013) Pre-conditioning factors and susceptibility assessments of Wenchuan earthquake landslide at the Zhouqu segment of Bailongjiang basin, China. J Geol Soc India 82(5):575-582. https://doi.org/10.1007/s12594-013-0190-8

Berardino P, Fornaro G, Lanari R, Sansosti E (2002) A new algorithm for surface deformation monitoring based on small baseline differential SAR interferograms. IEEE Trans Geosci Remote Sens 40(11):2375-2383. https://doi.org/10.1109/TGRS.2002.803792

Bi Y, Tang Y, Zhang M, Feng W, Li F (2016) Review of regional tectonics of Longnan. Open J Nat Sci 4(2):137-144 (in Chinese). https://doi.org/10.12677/ OJNS.2016.42017

Bonì R, Pilla G, Meisina C (2016) Methodology for detection and interpretation of ground motion areas with the ADInSAR time series analysis. Remote Sens 8(8):686

Bouali EH, Oommen T, Escobar-Wolf R (2017) Mapping of slow landslides on the Palos Verdes Peninsula using the California landslide inventory and persistent scatterer interferometry. Landslides 9:1-14

Burbank DW, Anderson RS (1985) Tectonic geomorphology. J Geol Educ 32:193-205 Bürgmann R, Rosen PA, Fielding EJ (2000) Synthetic aperture radar interferometry tomeasure Earth's surface topography and its deformation. Annu Rev Earth Planet Sci 28(1):169-209. https://doi.org/10.1146/annurev.earth.28.1.169

Calvello M, Peduto D, Arena L (2017) Combined use of statistical and DInSAR data analyses to define the state of activity of slow-moving landslides. Landslides 14(2):473-489

Chen F, Lin H, Zhou W, Hong T, Wang G (2013) Surface deformation detected by ALOS PALSAR small baseline SAR interferometry over permafrost environment of Beiluhe section, Tibet Plateau, China. Remote Sens Environ 138:10-18

Chen G, Meng X, Tan L, Zhang F, Qiao L (2014) Comparison and combination of different models for optimal landslide susceptibility zonation. Q J Eng Geol Hydrogeol 47(4):283-306

Cigna F, Bianchini S, Casagli N (2013) How to assess landslide activity and intensity with persistent scatterer interferometry (PSI): the PSI-based matrix approach. Landslides 10(3):267-283

Cigna F, Bateson LB, Jordan CJ, Dashwood C (2014) Simulating SAR geometric distortions and predicting persistent scatterer densities for ERS-1/2 and ENVISAT C-band SAR and InSAR applications: Nationwide feasibility assessment to monitor the landmass of great Britain with SAR imagery. Remote Sens Environ 152:441-466. https://doi.org/ 10.1016/j.rse.2014.06.025

Colesanti C, Wasowski J (2006) Investigating landslides with space-borne synthetic aperture radar (SAR) interferometry. Eng Geol 88(3):173-199. https://doi.org/ 10.1016/j.enggeo.2006.09.013

Costantini M (1998) A novel phase unwrapping method based on network programming. IEEE Trans Geosci Remote Sens 36(3):813-821. https://doi.org/10.1109/36.673674

Crosta G, Frattini P, Agliardi F (2013) Deep seated gravitational slope deformations in the European Alps. Tectonophysics 605:13-33

Cui P, Zhou GG, Zhu X, Zhang J (2013) Scale amplification of natural debris flows caused by cascading landslide dam 
failures. Geomorphology 182:173-189. https://doi.org/ 10.1016/j.geomorph.2012.11.009

Del Soldato M, Bianchini S, Calcaterra D, De Vita P, Di Martire D, Tomás R, Casagli N (2017) A new approach for landslide-induced damage assessment. Geomat Nat Haz Risk 8(2):1524-1537. https://doi.org/10.1080/19475705.2017.1347896

Dewey JF, Burke KC (1973) Tibetan, Variscan, and Precambrian basement reactivation: products of continental collision. J Geol 81(6):683-692. https://doi.org/10.1086/627920

Dijkstra, et al. (2012) Geomorphic controls and debris flows - the 2010 Zhouqu disaster, China. In: Proceedings of the 11th international symposium on landslides (ISL) and the 2nd North American Symposium on Landslides

Goldstein RM, Werner CL (1998) Radar interferogram filtering for geophysical applications. Geophys Res Lett 25(21):4035-4038. https://doi.org/10.1029/1998GL900033 Handwerger AL, Roering JJ, Schmidt DA, Rempel AW (2015) Kinematics of earthflows in the Northern California Coast Ranges using satellite interferometry. Geomorphology 246:321-333. https://doi.org/10.1016/j.geomorph.2015.06.003

Hanssen RF (2001) Radar interferometry: data interpretation and error analysis, vol 2. Springer Sci \& Business Media. https://doi.org/10.1007/0-306-47633-9

Herrera G, Gutiérrez F, García-Davalillo JC, Guerrero J, Notti D, Galve JP, FernándezMerodo JA, Cooksley G (2013) Multi-sensor advanced DInSAR monitoring of very slow landslides: the Tena Valley case study (Central Spanish Pyrenees). Remote Sens Environ 128(1):31-43. https://doi.org/10.1016/j.rse.2012.09.020

Huang R, Li WL (2009) Analysis of the geo-hazards triggered by the 12 May 2008 Wenchuan Earthquake, China. Bull Eng Geol Environ 68(3):363-371. https://doi.org/ 10.1007/s10064-009-0207-0

Huang X, Yang W, Zhang C, Shen J, Liu T (2013) The formation mechanism of Suoertou landslide in PingdingHuama fault zone, Southern Gansu. Geol Bull Chin 32(12):1936- 1942 (in Chinese)

Hungr O, Leroueil S, Picarelli L (2014) The Varnes classification of landslide types, an update. Landslides 11(2):167194

Jiang S, Wen BP, Zhao C, Li RD, Li ZH (2016) Kinematics of a giant slow-moving landslide in Northwest China: constraints from high resolution remote sensing imagery and GPS monitoring. J Asian Earth Sci 123:34-46. https://doi.org/10.1016/j.jseaes.2016.03.019 Kirby E, Harkins N (2013) Distributed deformation around the eastern tip of the Kunlun fault. Int J Earth Sci 102(7):1759-1772. https://doi.org/10.1007/s00531-013-0872-X

Korup O, Densmore AL, Schlunegger F (2010) The role of landslides in mountain range evolution. Geomorphology 120(1): 77 - 90. https://doi.org/10 . 1016/ j.geomorph.2009.09.017

Malet JP, Laigle D, Remaître A, Maquaire O (2005) Triggering conditions and mobility of debris flows associated to complex earthflows. Geomorphology 66(1):215-235. https://doi.org/10.1016/j.geomorph.2004.09.014

Mansour MF, Morgenstern NR, Martin CD(2011) Expected damage from displacement of slowmoving slides. Landslides 8(1):117-131. https://doi.org/10.1007/s10346-010-0227-7

Meisina C, Zucca F, Notti D, Colombo A, Cucchi A, Savio G, Giannico C, Bianchi M (2008) Geological interpretation of PSInSAR data at regional scale. Sensors 8(11):7469-7492. https://doi.org/10.3390/s8117469

Meng XM, Chen G, Guo P, Xiong MQ, Wasowski J (2013) Research of landslides and debris flows in Bailong River Basin: progress and prospect. Mar Geol Quat Geol 33(4):1-15 (in Chinese). https://doi.org/10.3724/SP.J.1140.2013.04001

Molnar P, Stock JM (2009) Slowing of India's convergence with Eurasia since 20 Ma and its implications for Tibetan mantle dynamics. Tectonics 28(3). https://doi.org/10.1029/ 2008TC002271

Necsoiu M, McGinnis RN, Hooper DM (2014) New insights on the Salmon Falls Creek Canyon landslide complex based on geomorphological analysis and multitemporal satellite InSAR techniques. Landslides 11(6):1141-1153. 
https://doi.org/10.1007/ s10346-014-0523-8

Notti D, Davalillo J, Herrera G, Mora O (2010) Assessment of the performance of X-band satellite radar data for landslide mapping and monitoring: Upper Tena Valley case study. Nat Hazards Earth Syst Sci 10(9):1865-1875. https://doi.org/10.5194/nhess-10- 1865-2010

Notti D, Herrera G, Bianchini S, Meisina C, García-Davalillo JC, Zucca F (2014) A methodology for improving landslide PSI data analysis. Int J Remote Sens 35(6):2186-2214

Novellino A, Cigna F, Brahmi M, Sowter A, Bateson L, Marsh S (2017) Assessing the feasibility of a national InSAR ground deformation map of Great Britain with Sentinel- Geosciences 7(19):1-14

Osmanoğlu B, Sunar F, Wdowinski S, Cabral-Cano E (2016) Time series analysis of InSAR data: methods and trends. ISPRS J Photogramm 115:90-102. https://doi.org/10.1016/ j.isprsjprs.2015.10.003

Pepe A, Lanari R (2006) On the extension of the minimum cost flow algorithm for phase unwrapping of multitemporal differential SAR interferograms. IEEE Trans Geosci Remote Sens 44(9):2374-2383. https://doi.org/10.1109/TGRS.2006.873207

Sarmap (2005) http://www.sarmap.ch/

Scheidegger A, Ai N (1987) Clay slides and debris flow in Wudu region. J Soil Water Conserv 1(2):19-27

Schlögel R, Doubre C, Malet J-P, Masson F (2015) Landslide deformation monitoring with ALOS/PALSAR imagery: a D-InSAR geomorphological interpretation method. Geomorphology 231:314-330. https://doi.org/10.1016/j.geomorph.2014.11.031

Schlögel R, Malet J-P, Doubre C, Lebourg T (2016) Structural control on the kinematics of the deep-seated la Clapière landslide revealed by L-band InSAR observations. Landslides 13(5):1005-1018. https://doi.org/10.1007/s10346015-0623-0

Schuster RL, Highland LM (2007) The Third Hans Cloos Lecture. Urban landslides: socioeconomic impacts and overview of mitigative strategies. Bull Eng Geol Environ 66(1):1-27. https://doi.org/10.1007/s10064-006-0080Z

Stimely LL (2009) Characterizing landslide movement at the Boulder Creek Earthflow, Northern California, using Lband InSAR (Doctoral dissertation, University of Oregon) Sun Q, Zhang L, Ding X, Hu J, Li Z, Zhu J (2015) Slope deformation prior to Zhouqu, China landslide from InSAR time series analysis. Remote Sens Environ 156:45-57. https://doi.org/10.1016/j.rse.2014.09.029

Tang C, Zhu J, Qi X, Ding J (2011) Landslides induced by the Wenchuan earthquake and the subsequent strong rainfall event: a case study in the Beichuan area of China. Eng Geol 122(1):22-33. https://doi.org/10.1016/j.enggeo.2011.03.013

Teshebaeva K, Roessner S, Echtler H, Motagh M, Wetzel H-U, Molodbekov B (2015) ALOS/ PALSAR InSAR timeseries analysis for detecting very slow-moving landslides in Southern Kyrgyzstan. Remote Sens 7(7):8973-8994. https://doi.org/10.3390/ rs70708973

Tomás R, Li Z, Lopez-Sanchez JM, Liu P, Singleton A (2016) Using wavelet tools to analyse seasonal variations from InSAR time-series data: a case study of the Huangtupo landslide. Landslides 13(3):437-450

Travelletti J, Malet JP, Delacourt C (2014) Image-based correlation of laser scanning point cloud time series for landslide monitoring. Int J Appl Earth Obs Geoinf 32:1-18. https://doi.org/10.1016/j.jag.2014.03.022

Van Asch TW, Van Beek LPH, Bogaard TA (2007) Problems in predicting the mobility of slow-moving landslides. Eng Geol 91(1):46-55. https://doi.org/10.1016/ j.enggeo.2006.12.012

Van Der Woerd J, Tapponnier P, Ryerson FJ et al (2002) Uniform postglacial slip-rate along the central $600 \mathrm{~km}$ of the Kunlun Fault (Tibet), from 26Al, 10Be, and 14C dating of riser offsets, and climatic origin of the regional 
morphology. Geophys J Int 148(3):356-388. https://doi.org/10.1046/j.1365-246x.2002.01556.x

Varnes DJ (1978) Slope movement types and processes. Trans Res Board Spec Rep 176:11-33

Wasowski J, Bovenga F (2014) Investigating landslides and unstable slopes with satellite multi temporal interferometry: current issues and future perspectives. Eng Geol 174:103-138. https://doi.org/10.1016/j.enggeo.2014.03.003

Wasowski J, Bovenga F, Dijkstra T, Meng X, Nutricato R, Chiaradia MT (2014) Persistent scatterers interferometry provides insight on slope deformations and landslide activity in the mountains of Zhouqu, Gansu, China. In: Landslide science for a safer geoenvironment Springer, pp 359-364. https://doi.org/10.1007/978-3-319-050508_56

Xiong M, Meng X, Wang S, Guo P, Li Y, Chen G, Qing F, Cui Z, Zhao Y (2016) Effectiveness of debris flow mitigation strategies in mountainous regions. Prog Phys Geogr 40(6):768-793

Yang WM, Huang X, Zhang YS, Liu T (2013) The deformation characteristics of the landslide along Pingding-Huama active fault zone and its prevention and control. Geol Bull Chin 32(12):1925-1935 (in Chinese)

Yin Y, Wang F, Sun P (2009) Landslide hazards triggered by the 2008 Wenchuan earthquake, Sichuan, China. Landslides 6(2):139-152

Yu JX, Zheng WJ, Yuan DY, Pang JZ, Liu XW, Liu BY (2012) Late quaternary active chatacteristics and slip-rate of Pingding-Huama fault, the eastern segment of Guanggaishan-Diesan fault zone (west Qingling mountain). Quat Sci 32(5):957-967 (in Chinese)

Yu G, Zhang M, Cong K, Pei L (2015) Critical rainfall thresholds for debris flows in Sanyanyu, Zhouqu County, Gansu Province, China. Q J Eng Geol Hydrogeol 48(3- 4):224-233. https://doi.org/10.1144/qjegh2014-078

Zhang Y, Meng XM, Chen G, Qiao L, Zeng R, Chang J (2016) Detection of geohazards in the Bailong River Basin using synthetic aperture radar interferometry. Landslides 13(5):1273-1284

Zhao CY, Lu Z, Zhang Q, de la Fuente J (2012) Large-area landslide detection and monitoring with ALOS/PALSAR imagery data over Northern California and Southern Oregon, USA. Remote Sens Environ 124:348-359

Zhao R, Li ZW, Feng GC, Wang QJ, Hu J (2016) Monitoring surface deformation over permafrost with an improved SBAS-InSAR algorithm: with emphasis on climatic factors modeling. Remote Sens Environ 184:276-287. https://doi.org/10.1016/ j.rse.2016.07.019

Zheng WJ, Liu XW, Yu JX, Yuan DY, Zhang PZ, Ge WP, Pang JZ, Liu BY (2016) Geometry and late Pleistocene slip rates of the Liangdang-Jiangluo fault in the western Qinling mountains, NW China. Tectonophysics 687:1-13 